\title{
International Great Inflation and Common Monetary Policy ${ }^{\mathrm{a}}$
}

\author{
Jacek Suda \\ Narodowy Bank Polski \\ Świętokrzyska 11/21, 00-919 Warsaw, Poland \\ Email: jacek.suda@nbp.com. \\ http://www. jaceksuda.com. \\ Anastasia S. Zervou ${ }^{\mathrm{b}}$ \\ Texas A\&M University \\ 4228 TAMU, College Station, TX 77843, USA \\ Email: azervou@tamu.edu \\ https://sites.google.com/site/anastasiazervouwebpage, \\ tel. +1 979-8457309, fax. +1 979-8478757.
}

This version: May 13, 2016

${ }^{a}$ We are very grateful to James Morley for his direction and support. We are very grateful to ChangJin Kim for sharing computer routines. We also thank James Bullard, Anindya Banerjee, Siddhartha Chib, Yunjong Eo, Anna Mikusheva, Athanasios Orphanides, B. Ravikumar, Barbara Rossi, Aarti Singh, Thanasis Stengos, the editor, two referees, participants of seminars at the University of Houston, Texas A\&M University, Banque de France, Bank of Netherlands, Tilburg University, the Midwest Macroeconomics Conference, the Conference on Computing in Economics and Finance, the 15th Texas Camp Econometrics, the 8th Conference on Research on Economic Theory \& Econometrics and the Midwest Econometric Group for helpful comments.

${ }^{\mathrm{b}}$ Corresponding author 


\section{International Great Inflation}

\section{Anastasia S. Zervou}

Texas A\&M University

4228 TAMU, College Station, TX 77843, USA

Email: azervou@tamu.edu

https://sites.google.com/site/anastasiazervouwebpage, tel. +1 979-8457309, fax. +1 979-8478757. 


\begin{abstract}
We study whether monetary authorities in the G7 countries were changing their responses to inflation in a similar manner during and following the Great Inflation era. We find that the common to the G7 countries inflation pattern during the Great Inflation period could be associated with a common pattern in the monetary policy response to inflation: we find that until the early 1980s monetary authorities in the G7 countries responded mildly to inflation, systematically fought it throughout the 1980s and lessened again their response during the 2000s. The estimated Taylor rule coefficients on inflation are cointegrated, implying the existence of a long run relationship in the responses to inflation during and after the Great Inflation period. At the same time, principal component analysis of the residuals of the estimated Taylor rules indicates that the shocks' structure cannot account enough for the monetary policies' comovements. We interpret these findings as suggestive of common monetary policy patterns.

JEL classification: E52; E58; C22.
\end{abstract}

Keywords: International Monetary Policy, International Great Inflation, Time Varying Parameter Model. 


\section{Introduction}

The Great Inflation was an international phenomenon. As Figures 1 and 2 show, all of the G7 countries experienced higher than usually inflation at approximately the same period, from the mid-1960s until the mid-1980s. We follow the Friedman and Allen's (1970) view that "inflation is always and everywhere a monetary phenomenon" and explore it in the international context. Specifically, we approximate monetary policy with a forward-looking, time-varying parameter Taylor rule and we estimate the G7 monetary authorities' responses to inflation. Our results indicate that the G7 countries had been responding in a similar manner to inflation during the Great Inflation period: they were responding less to inflation during the 1970s and more from the mid-1980s until the mid-1990s. We find that these responses are cointegrated, indicating the existence of a long run relationship across the monetary policies in G7 countries. These results suggest that the common conduct of monetary policy may be at the origin of the common inflation patterns in the G7 countries during the Great Inflation period. ${ }^{1}$

Figure 1 HERE

Most of the existing research concentrates on explaining the Great Inflation in the United States. Figure 1 illustrates that after 1965 the CPI inflation in the US rose, reached

$6 \%$ in 1969 and peaked at $15.7 \%$ in 1980 . While some of the proposed explanations are based on the oil price shock or the fiscal policy, it is the monetary policy that has been at the center of attention. ${ }^{2}$ DeLong (1997) argues that during the 1970s, the Federal Reserve was biased against sustaining low inflation due to the relatively recent, at that time, experience of deflation and high unemployment durind the Great Depression. Clarida, Galí, and Gertler (2000) suggest that during the pre-Volker era, the nominal interest rate's response to inflation was less than one to one creating a self-fulfilling expectations trap and leading to further inflation increase. ${ }^{3}$ Romer and Romer $(2002,2004)$ claim that during the $1960 \mathrm{~s}$ and 1970s, monetary authorities treated inflation as a cost-push phenomenon, believing in a long-run tradeoff between inflation and unemployment which was discouraging them 
from aiming at controlling inflation. ${ }^{4}$

Figure 2 HERE

However, the inflation pattern across developed countries seems strikingly similar to the one observed in the United States. Figure 2 shows that inflation was higher than usually at approximately the same period in all G7 countires, a feature that not all explanations of Great Inflation in the United States are able to account for. For example, observing Figure 2 we see that while the general inflation pattern is shared among the countries considered, in many countries (e.g. France, UK and Japan) inflation had started increasing before the first oil shock. Moreover, the self-fulfilling expectations situation requires the trigger of the oil price shock, and thus the former critique applies also here. Thus, the oil shock does not seem to be the most important reason behind the common patterns of inflation across the G7 countries. $^{5}$

In this paper we consider the Great Inflation as an international phenomenon and attempt to use information from the cross-sectional dimension to contribute towards identifying its cause.

We study the evolution of monetary policy decisions in order to explore monetary authorities' responsibility in sustaining high inflation in the G7 countries during the 1970s. In our empirical model we approximate these decisions using a forward-looking Taylor rule for the nominal interest rate and estimate monetary authorities' response to inflation, output gap, and lagged interest rate. ${ }^{6}$ In preliminary analysis we find evidence of a specific timevariation in the conduct of monetary policy. We then explore the evolution of monetary policy decisions over time using the time-varying parameter framework (Kim and Nelson, 1989, 2006). This framework allows monetary authorities to change their policies in terms of their response to inflation, output gap and in terms of smoothing behavior.

In addition, we examine if these changes had similar pattern in the G7 countries during the Great Inflation period. We explore the possibility of a long run, cointegrated relationship in monetary policy responses across countries at that period. The multi-country dimension of our analysis permits to examine whether there is commonality in the learning 
processes of the monetary authorities. Finally, we apply principal component analysis in the residuals of the Taylor rules in order to examine if there are strong common components in the shocks structure of the countries considered. In this way, we are able to asses whether it was a common policy or common shocks that led to common inflation patterns.

We find that the developed countries in our sample (Canada, France, Germany, Italy, Japan, UK and US) have not only similar inflation patterns but also similar monetary policy patterns. Specifically, we show that during the 1970s monetary authorities in G7 countries were reluctant to increase interest rates targets in response to high inflation, while they were responding aggressively to inflation later and until the mid-1990s. We observe that after the mid-1990s the interest rate reaction to inflation diminishes in many of the G7 countries. Possibly, as inflation decreased and stabilized central banks assigned lower importance to it. Previous studies (Kim, Kishor, and Nelson, 2006 and FernandezVillaverde, Guerron, and Rubio-Ramirez, 2010) document such a result for the US and we are able to find it also in other developed countries.

Furthermore, we find that the monetary authorities in the G7 countries exhibit a cointegrated relationship in their inflation responses during the Great Inflation period. The existence of common stochastic trend in the policy parameters indicates that there is a long-run relationship in policy conduct concerning inflation. In particular, if we exclude Japan we cannot reject the hypothesis that there is a single stochastic trend that is responsible for the long-run changes in monetary policy in almost all G7 countries. Thus, the common inflation patterns observed during the Great Inflation era are indeed related to common monetary policy patterns.

Taking into account previous literature on common shocks and synchronized business cycles (Kose et al., 2003; Guerron, 2013), our results could indicate reaction of monetary authorities to common shocks. To address this issue, we perform principal component analysis in the residuals of the G7 Taylor rules but we do not find strong common component. This result indicates that it was mostly common policies rather than common shocks that contributed towards the international phenomenon of the Great Inflation. 
Previous work (for example, DeLong, 1997; Sargent, 1999; Romer and Romer, 2002, 2004; Cogley and Sargent, 2005, Sargent et al., 2006; DiCecio and Nelson, 2009) proposes that the Great Inflation of the 1970s was the result of perceptions of what monetary policy is able and ought to do; these perception encouraged accommodative policy during the Great Inflation era. ${ }^{7}$ Romer (2005) argues that these perceptions were shared in a number of countries as policy makers read the same academic papers and form similar beliefs about the role of monetary policy at any point in time. Furthermore, Nelson (2005a) suggests a unified framework of beliefs prevailing among various developed countries. If these arguments are correct we should find similar cross-country patterns not only in inflation, as Figure 2 indicates, but also in the monetary authorities' response to inflation. Our empirical results support this argument and empirically identify the missing link in the literature on the ideas-driven common inflation pattern by finding a common pattern in monetary policies response to inflation.

The rest of the paper is organized as follows. Section 2 presents preliminary analysis emphasizing the need for using the time varying parameter model. Section 3 introduces the model and Section 4 presents the estimation technique. Section 5 describes the data and Section 6 presents the results. Section 7 discusses narrative evidence. Finally, Section 8 concludes.

\section{Preliminary Analysis}

To establish whether monetary policy evolved over time, we estimate a simple Taylor-type rule and analyze it by splitting the sample and by using a rolling sample estimation. In particular, we estimate the following simple rule with smoothing:

$$
\begin{gathered}
r_{i, t}=\left(1-\theta_{i}\right)\left(\beta_{0, i}+\beta_{1, i} \pi_{i, t}+\beta_{2, i} y_{i, t}\right)+\theta_{i} r_{i, t-1}+e_{i, t} \\
e_{i, t} \sim \text { i.i.d.N }\left(0, \sigma_{e_{i}}^{2}\right)
\end{gathered}
$$

where $r_{i, t}$ is the short term rate at time $t$ for country $i, \pi_{i, t}$ denotes the current inflation rate, $y_{i, t}$ is the average output gap at the current period for country $i, \theta_{i}$ denotes the 
smoothing parameter, and $e_{i, t}$ denotes a random disturbance term.

\section{Insert TABLE 1 HERE}

We first estimate the above Taylor rule for the G7 countries, splitting the sample in two parts, before and after 1979:2. ${ }^{8}$ The results are given at Table 1. From there we see a very characteristic pattern: consistently for all the countries considered the estimated

coefficients are larger in the second part of the sample compared to the first with the difference in estimated coefficients across two subsamples being statistically significant at $5 \%$ level for 3 out of 7 countries: Japan, the United Kingdom and the United States.

Next, we do rolling sample estimation of the simple Taylor rule given by equation (1). We use 80 periods window (20 years) and since the error term $e_{i, t}$ is likely to be correlated with the exogenous variables, we use generalized method of moments. ${ }^{9}$ The results can be seen in Figure 3. For example, the 1979 third quarter point refers to the estimate for the period 1969 third quarter to 1989 third quarter. We see that for all countries the inflation coefficient is low and below one in the early part of the sample but it exhibits an apparent upward movement from the middle and towards the end of the sample.

\section{Insert FIGURE 3 HERE}

Both the split sample and the rolling sample estimates indicate that for all G7 countries the coefficients on inflation in a monetary policy rule have been changing over time. Moreover, these changes indicate a specific and common to all countries pattern: they are low at the beginning but increase towards the end of the sample. In order to examine the specific pattern each country has followed and observe the change of the coefficients, it is essential to use the time-varying parameter model.

\section{The Empirical Model}

Given the results in the previous section, we use the time-varying parameter model to estimate monetary policy rules for the G7 countries: Canada, France, Germany, Italy, 
Japan, the UK and the US. In our model we follow previous literature and we approximate monetary policy with Taylor-type rules for all the countries and time periods considered. ${ }^{10}$ It is well known that, at times, several countries did not use such rule, for example the US during the Volcker period followed reserves targeting, and this could lead to model mis-specification. We believe this problem is less severe in our study given that we allow for many sources of variation in our model, as we explain below. Moreover, Goodfriend (1991) documents that although the US was not using such an interest rate rule during all periods, policy makers had it in mind when making policy decisions. Finally, we choose to include Japan in our sample because we are interested in its response to inflation during the Great Inflation period and before its liquidity trap.

We consider a forward-looking Taylor-type rule where the target short term rate $r_{i, t}^{*}$ and the actual short term rate $r_{i, t}$ at time $t$ for country $i$ are specified as

$$
r_{i, t}^{*}=\beta_{0, i, t}^{*}+\beta_{1, i, t}\left(E_{t}\left(\pi_{i, t, J}\right)-\pi_{i, t}^{*}\right)+\beta_{2, i, t} E_{t}\left(y_{i, t, J}\right)
$$

and

$$
r_{i, t}=\left(1-\theta_{i, t}\right) r_{i, t}^{*}+\theta_{i, t} r_{i, t-1}+m_{i, t}, \quad 0<\theta_{t}<1
$$

where for country $i, \pi_{i, t}^{*}$ is the target inflation rate, $\pi_{i, t, J}$ is the inflation rate from period $t$ to period $t+J, y_{i, t, J}$ is the average output gap from period $t$ to period $t+J$ and $\beta_{0, i, t}^{*}$ is the target short term rate when both inflation and output gap are equal to their target values. $\theta_{i, t}$ denotes the smoothing parameter (also time-varying) and $m_{i, t}$ denotes the random disturbance term.

Rewriting equations (2) and (3) we obtain the equation to be estimated:

$$
\begin{gathered}
r_{i, t}=\left(1-\theta_{i, t}\right)\left(\beta_{0, i, t}+\beta_{1, i, t} \pi_{i, t}+\beta_{2, i, t} y_{i, t}\right)+\theta_{i, t} r_{i, t-1}+e_{i, t} \\
e_{i, t} \mid I_{t-1} \sim i . i . d . N\left(0, \sigma_{e_{i, t}}^{2}\right)
\end{gathered}
$$

where $\pi_{i, t}$ denotes the current inflation rate, $y_{i, t}$ is the average output gap at the current 
period for country $i, I_{t-1}$ summarizes information up to time $t-1$,

$$
\beta_{0, i, t}=\beta_{0, i, t}^{*}-\beta_{1, i, t} \pi_{i, t}^{*}
$$

and

$$
e_{i, t}=-\left(1-\theta_{i, t}\right)\left[\beta_{1, i, t}\left(\pi_{i, t}-E_{t}\left(\pi_{i, t+1}\right)\right)+\beta_{2, i, t}\left(y_{i, t}-E_{t}\left(y_{i, t+1}\right)\right)\right]+m_{i, t},
$$

where we let $J=1$.

Sims and Zha (2006) point out that the US interest rate instability could be due to the time-varying variance of the disturbances and not due to the time-varying parameters of the monetary policy reaction equation. As a result, a simple time-varying parameter model that does not account for a changing variance of the error term could produce spurious variation in the time-varying parameters. To address this issue we allow for a $\operatorname{GARCH}(1,1)$ process for the variance of the error term:

$$
\sigma_{e_{i, t}}^{2}=a_{0}+a_{1} e_{i, t-1}^{2}+a_{2} \sigma_{e_{i, t-1}}^{2}
$$

We assume that the time varying coefficients follow random walk dynamics:

$$
\begin{aligned}
& \beta_{k, i, t}=\beta_{k, i, t-1}+\epsilon_{k, i, t}, \\
& \epsilon_{k, i, t} \sim \text { i.i.d.N }\left(0, \sigma_{\epsilon, k, i}^{2}\right), \quad k=0,1,2,3 .
\end{aligned}
$$

In addition, the smoothing parameter $\theta_{i, t}$ is constrained to take values between 0 and 1 by setting it as follows:

$$
\theta_{i, t}=\frac{1}{1+\exp \left(-\beta_{3, i, t}\right)}
$$

Our system of equations consists of the interest rate equation (4) and equations (6), (7) and (8) that describe the GARCH error term and the transition of the time-varying coefficients.

The above specification is subject to endogeneity problem as regressors are correlated with the error term. If endogeneity is not captured, then the coefficients' estimates would be biased and the estimates would not recover the effect of changes of expected inflation 
on the nominal interest rate, which is exactly what we are interested in. ${ }^{11}$ It is also a nonlinear model which we are going to linearize before we use the Kalman filter to estimate it. In the proceeding subsections we describe how we address these issues.

The modeling choice of using the time-varying single equation framework comes from our attempt to reduce the number of parameters to be estimated. ${ }^{12}$ An alternative to a single equation model could be the time-varying multi-equation framework (see for example Primiceri, 2005; Sims and Zha, 2006). That choice would not come without a cost, though, as we would still have to make some assumptions to reduce the dimensionality of the system. For example, we could use a time-varying VAR model with only a few countries, or a wider set of countries as we do, but at the cost of tight priors or high uncertainty around the coefficient estimates. Most importantly, our choice of using the single-equation approach allows us to add complexity in the model at the place we find essential for our purposes, especially referring to the instrumental variables technique addressing endogeneity. ${ }^{13}$

In subsection 3.1 we follow Kim (2006) in implementing a two-step estimation technique, in order to account for endogeneity. ${ }^{14}$ In subsection 3.2 we address the non-linearities in the estimation of coefficients of the monetary policy rule.

\subsection{Endogeneity}

In equation (4), the regressors are correlated with the error term $e_{i, t}$ given by equation (5). This is a usual issue in estimating Taylor-type of rules with current data (see Clarida et al., 2000), which requests usage of instrumental variables. To address endogeneity in the time varying framework, we employ instrumental variables and the augmented Kalman filter introduced by Kim (2006, 2008) and Kim and Nelson (2006).

Let $\mathbf{z}_{\mathbf{i}, \mathbf{t}}$ be a $L \mathrm{x} 1$ vector of instruments not correlated with $e_{i, t}$. Then, we can write the instrumental variables equations:

$$
\pi_{i, t}=\mathbf{z}_{\mathbf{i}, \mathbf{t}}{ }^{\prime} \boldsymbol{\delta}_{\boldsymbol{\pi}, i, \boldsymbol{t}}+v_{\pi, i, t}, \quad v_{\pi, i, t} \sim \text { i.i.d.N }\left(0, \sigma_{\pi, i, t}^{2}\right)
$$


and

$$
y_{i, t}=\mathbf{z}_{\mathbf{i}, \mathbf{t}}{ }^{\prime} \boldsymbol{\delta}_{\boldsymbol{y}, \boldsymbol{i}, \boldsymbol{t}}+v_{y, i, t}, \quad v_{y, i, t} \sim i . i . d . N\left(0, \sigma_{y, i, t}^{2}\right),
$$

where $\boldsymbol{\delta}_{\boldsymbol{\pi}, \boldsymbol{i}, \boldsymbol{t}}$ is a $L \times 1$ vector of time-varying coefficients, $v_{\pi, i, t}=\sigma_{\pi, i, t} v_{\pi, i, t}^{*}, v_{y, i, t}=$ $\sigma_{y, i, t} v_{y, i, t}^{*}$, and $v_{\pi, i, t}^{*} \sim i . i . d . N(0,1)$, and $v_{y, i, t}^{*} \sim i . i . d . N(0,1)$ are the standard errors. Since there could be shocks that alter the relationship between the endogenous variables in the current period and the instruments, we allow for a time-varying relationship between the endogenous variables and the instruments. Such specification has a desirable economic interpretation: the time-varying model is employed when inflation and output gap are estimated and forecasted by the central bank. Parameters in equations (9) and (10) are assumed to follow a random walk process:

$$
\boldsymbol{\delta}_{\nu, i, t}=\boldsymbol{\delta}_{\nu, i, t-1}+\zeta_{\nu, i, t}, \quad \boldsymbol{\zeta}_{\nu, i, t} \sim i . i . d . N\left(\mathbf{0}_{\mathbf{L}}, \boldsymbol{\Sigma}_{\zeta, \nu, i}\right), \quad \nu=\pi, y,
$$

where $\boldsymbol{\zeta}_{\boldsymbol{\nu}, \boldsymbol{i}, \boldsymbol{t}}$ is a $L \times 1$ vector of disturbances for the transition of the IV coefficients, $\mathbf{0}_{\mathbf{L}}$ is a $L \times 1$ vector of zeros and $\boldsymbol{\Sigma}_{\boldsymbol{\zeta}, \boldsymbol{\nu}, \boldsymbol{i}}$ is a $L \times L$ diagonal variance-covariance matrix of the IV coefficients.

In addition, we allow the error terms in the instrumental variable equations to be heteroscedastic and to follow a $\operatorname{GARCH}(1,1)$ process:

$$
\sigma_{\nu, i, t}^{2}=a_{\nu, i, 0}+a_{\nu, i, 1} v_{\nu, i, t-1}^{2}+a_{\nu, i, 2} \sigma_{\nu, i, t-1}^{2}, \quad \nu=\pi, y
$$

Given the oil price shocks of 1973 and 1979, it is important to allow for changing variance of the shocks affecting inflation and output gap. Moreover, our specification allows us to take into account changing uncertainty about future expected inflation and output gap estimates. ${ }^{15}$

Using equation (11), we can decompose the instrumental variable equations (9) and (10) into predicted values and prediction errors, as follows:

$$
\pi_{i, t}=\mathbf{z}_{\mathbf{i}, \mathbf{t}}{ }^{\prime} \boldsymbol{\delta}_{\boldsymbol{\pi}, i, \boldsymbol{t}-\mathbf{1}}+\eta_{\pi, i, t}, \quad \eta_{\pi, i, t} \mid z_{i, t} \sim \text { i.i.d.N }\left(0, f_{\pi, i, t}\right),
$$


and

$$
y_{i, t}=\mathbf{z}_{\mathbf{i}, \mathbf{t}}{ }^{\prime} \boldsymbol{\delta}_{\boldsymbol{y}, \boldsymbol{i , t - \mathbf { 1 }} \mathbf{1}}+\eta_{y, i, t}, \quad \eta_{y, i, t} \mid z_{i, t} \sim \text { i.i.d.N }\left(0, f_{y, i, t}\right),
$$

where $\eta_{\nu, i, t}=\boldsymbol{z}_{\boldsymbol{i}, \boldsymbol{t}}{ }^{\prime} \boldsymbol{\zeta}_{\boldsymbol{\nu}, \boldsymbol{i}, \boldsymbol{t}}+\sigma_{\nu, i, t} v_{\nu, i, t}^{*}$ for $\nu=\pi, y$.

The above model is estimated in two steps, as it is usual in the IV estimation. Step 1: Estimate the system of IV's, equations (9) - (12), and produce estimates for $\eta_{\pi, i, t}^{*}, \eta_{y, i, t}^{*}$, i.e., $\hat{\eta}_{\pi, i, t}^{*}, \hat{\eta}_{y, i, t}^{*}$. Step 2: Estimate the system of equations (7), (8) and (6) together with the following one:

$$
\begin{gathered}
r_{i, t}=\left(1-\theta_{i, t}\right)\left(\beta_{0, i, t}+\beta_{1, i, t} \pi_{i, t}+\beta_{2, i, t} y_{i, t}\right)+\theta_{i, t} r_{i, t-1}+\gamma_{\pi} \hat{\eta}_{\pi, i, t}^{*}+\gamma_{y} \hat{\eta}_{y, i, t}^{*}+u_{i, t} \\
u_{i, t}=\omega_{i, t}+\gamma_{\pi}\left(\eta_{\pi, i, t}^{*}-\hat{\eta}_{\pi, i, t}^{*}\right)+\gamma_{y}\left(\eta_{y, i, t}^{*}-\hat{\eta}_{, i, t}^{*}\right) .
\end{gathered}
$$

The main rational for this two-step approach is the following. The Kalman filter cannot be immediately applied because the regressors in equation (4) correlate with the error term. But if we decompose $e_{i, t}$ in two components, one that correlates with the regressors and one that does not, i.e., $e_{i, t}=\mathrm{E}\left[e_{i, t} \mid \pi_{i, t}, y_{i, t}\right]+\omega_{i, t}$, then we can run the Kalman filter in a model that explicitly models the endogenous part of $e_{i, t}$, and the exogenous error term, here $\omega_{i, t}$. To this end, we first compute $\mathrm{E}\left[e_{i, t} \mid \pi_{i, t}, y_{i, t}\right]=\rho_{\pi, i} \sigma_{e_{i, t}} \eta_{\pi, i, t}^{*}+\rho_{y, i} \sigma_{e_{i, t}} \eta_{y, i, t}^{*}$, for $\rho_{\pi, i}, \rho_{y, i}$ describing the correlation of the error term with the instruments. Next, we can compute $\omega_{i, t}=e_{i, t}-\mathrm{E}\left[e_{i, t} \mid \pi_{i, t}, y_{i, t}\right]$ that does not correlate with the regressors. Given that $\eta_{\pi, i, t}^{*}, \eta_{y, i, t}^{*}$ are not observed, we use estimates $\hat{\eta}_{\pi, i, t}^{*}, \hat{\eta}_{y, i, t}^{*}$ in equation (15). Now, given that the error term is exogenous $\left(\omega_{i, t}\right.$ does not correlate with $\eta_{\pi, i, t}^{*}$ or $\left.\eta_{y, i, t}^{*}\right)$, we can apply the augmented Kalman filter. ${ }^{16}$

\subsection{Non-linear Estimation}

Our equation of interest (15) is non-linear with respect to the coefficients that we want to estimate, given that part of it is multiplied with $\left(1-\theta_{i, t}\right) .{ }^{17}$ Following Kim and Nelson (2006) we linearize the model around $\boldsymbol{\beta}_{\boldsymbol{i}, \boldsymbol{t}}=\boldsymbol{\beta}_{\boldsymbol{i}, \boldsymbol{t} \mid \boldsymbol{t - 1}}=\mathrm{E}\left(\boldsymbol{\beta}_{\boldsymbol{i}, t} \mid \boldsymbol{I}_{\boldsymbol{t}-\mathbf{1}}\right)$ using first order Taylor 
expansion. Therefore, the linearization of equation (15) yields:

$$
\begin{aligned}
r_{i, t} & =C_{i, t}+\mathbf{X}_{\mathbf{i}, \mathbf{t}}{ }^{\prime} \boldsymbol{\beta}_{\boldsymbol{i}, \boldsymbol{t}}+\gamma_{\pi} \hat{\eta}_{\pi, i, t}^{*}+\gamma_{y} \hat{\eta}_{y, i, t}^{*}+u_{i, t}, \\
u_{i, t} & =\omega_{i, t}+\gamma_{\pi}\left(\eta_{\pi, i, t}^{*}-\hat{\eta}_{\pi, i, t}^{*}\right)+\gamma_{y}\left(\eta_{y, i, t}^{*}-\hat{\eta}_{, i, t}^{*}\right), \\
\omega_{i, t} & \sim \operatorname{i.i.d.N}\left(0,\left(1-\rho_{\pi, i}^{2}-\rho_{y, i}^{2}\right) \sigma_{e_{i, t}}^{2}\right),
\end{aligned}
$$

where $\boldsymbol{\beta}_{\boldsymbol{i}, \boldsymbol{t}}=\left[\begin{array}{llll}\beta_{0, i, t} & \beta_{1, i, t} & \beta_{2, i, t} & \beta_{3, i, t}\end{array}\right]^{\prime}$ and

$C_{i, t}=\frac{r_{i, t-1}}{1+\exp \left(-\beta_{3, i, t \mid t-1}\right)}-\frac{\exp \left(-\beta_{3, i, t \mid t-1}\right) \beta_{3, i, t \mid t-1}\left(r_{i, t-1}-\beta_{0, i, t \mid t-1}-\beta_{1, i, t \mid t-1} \pi_{i, t}-\beta_{2, i, t \mid t-1} y_{i, t}\right)}{\left(1+\exp \left(\beta_{3, i, t \mid t-1}\right)\right)^{2}}$,

and

$$
\mathbf{X}_{\mathbf{i}, \mathbf{t}}=\left[\begin{array}{c}
1-\frac{1}{1+\exp \left(-\beta_{3, i, t \mid t-1}\right)} \\
\pi_{i, t}-\frac{\pi_{i, t}}{1+\exp \left(-\beta_{3, i, t \mid t-1}\right)} \\
y_{i, t}-\frac{y_{i, t}}{1+\exp \left(-\beta_{3, i, t \mid t-1}\right)} \\
\frac{\exp \left(-\beta_{3, i, t \mid t-1}\right)\left(r_{i, t-1}-\beta_{0, i, t \mid t-1}-\beta_{1, i, t \mid t-1} \pi_{i, t}-\beta_{2, i, t \mid t-1} y_{i, t}\right)}{\left(1+\exp \left(\beta_{3, i, t \mid t-1}\right)\right)^{2}}
\end{array}\right] .
$$

After the linearization, the interest rate is linear with respect to the $\beta \mathrm{s}$ in (16).

\section{Empirical Strategy}

We look for a long-run relationship between monetary policy changes in the G7 countries. To this end we employ a two-stage procedure. In the first stage of our empirical analysis, we estimate the Taylor rule for each country. We recover the estimated time-varying policy parameters and use them in the second stage, where we look for a cointegrating relationship between the estimated series. We also perform principal component analysis on the Taylor rules' residuals, generated at the first stage of our empirical analysis. Below we describe these stages briefly and present more detailed analysis in the Appendices A and B. 


\subsection{Stage A Estimation: Country by Country Taylor Rule}

Given the regressors' endogeneity, we employ a two-step estimation procedure introduced by Kim (2006) and used by Kim and Nelson (2006), Kishor (2012), Baxa et al. (2014), as briefly outlined in Section 3.1. At the first step we estimate the system of IVs equations (9) - (12), and generate estimates $\hat{\eta}_{\pi, i, t}^{*}$ and $\hat{\eta}_{y, i, t}^{*}$. Then we estimate the linearized system of equation (16)-(18) together with equations (7), (8) and (6), taking into consideration the non-linearity of the model and the heteroscedastic disturbances. The model has the following state-space representation:

$$
\begin{aligned}
& r_{i, t}=C_{i, t \mid t-1}+\left[\begin{array}{ll}
\mathbf{X}_{\mathbf{i}, \mathbf{t} \mid \mathbf{t}-\mathbf{1}}^{\prime} & 1
\end{array}\right]\left[\begin{array}{c}
\boldsymbol{\beta}_{\boldsymbol{i}, t} \\
\omega_{i, t}
\end{array}\right]+\rho_{\pi, i} \sigma_{e_{i, t}} \eta_{\pi, i, t \mid t-1}^{*}+\rho_{y, i} \sigma_{e_{i, t}} \eta_{y, i, t \mid t-1}^{*}, \\
& \left(r_{i, t}=C_{i, t \mid t-1}+\tilde{\boldsymbol{X}}_{\mathbf{i}, \mathbf{t} \mid \mathbf{t}-\mathbf{1}}^{\prime} \tilde{\boldsymbol{\beta}}_{\boldsymbol{i}, t}+\rho_{\pi, i} \sigma_{e_{i, t}} \eta_{\pi, i, t \mid t-1}^{*}+\rho_{y, i} \sigma_{e_{i, t}} \eta_{y, i, t \mid t-1}^{*}\right)
\end{aligned}
$$

and

$$
\begin{gathered}
{\left[\begin{array}{c}
\boldsymbol{\beta}_{\boldsymbol{i}, \boldsymbol{t}} \\
\omega_{i, t}
\end{array}\right]=\left[\begin{array}{cc}
\mathbf{I}_{\mathbf{4}} & \mathbf{0}_{\mathbf{4}} \\
\mathbf{0}_{\mathbf{4}}{ }^{\prime} & 0
\end{array}\right]\left[\begin{array}{c}
\boldsymbol{\beta}_{\boldsymbol{i}, \boldsymbol{t}-\mathbf{1}} \\
\omega_{i, t-1}
\end{array}\right]+\left[\begin{array}{c}
\epsilon_{i, t} \\
\omega_{i, t}
\end{array}\right],} \\
{\left[\begin{array}{c}
\boldsymbol{\epsilon}_{\boldsymbol{i}, \boldsymbol{t}} \\
\omega_{i, t}
\end{array}\right] \sim i . i . d . N\left(\left[\begin{array}{c}
\mathbf{0}_{\mathbf{4}} \\
0
\end{array}\right],\left[\begin{array}{cc}
\boldsymbol{\Sigma}_{\boldsymbol{\epsilon}, \boldsymbol{i}} & \mathbf{0}_{\mathbf{4}} \\
\mathbf{0}_{\mathbf{4}}{ }^{\prime} & \left(1-\rho_{\pi, i}^{2}-\rho_{y, i}^{2}\right) \sigma_{e_{i, t}}^{2}
\end{array}\right]\right),} \\
\left(\tilde{\boldsymbol{\beta}}_{\boldsymbol{i}, \boldsymbol{t}}=\mathbf{B} \tilde{\boldsymbol{\beta}}_{\boldsymbol{i}, \boldsymbol{t}-\mathbf{1}}+\tilde{\boldsymbol{\epsilon}}_{\boldsymbol{i}, \boldsymbol{t}}, \quad \tilde{\boldsymbol{\epsilon}}_{\boldsymbol{i}, \boldsymbol{t}} \sim \operatorname{i.i.d.N}\left(\mathbf{0}_{\mathbf{5}}, \boldsymbol{\Sigma}_{\tilde{\boldsymbol{\epsilon}}, \boldsymbol{i}}\right)\right)
\end{gathered}
$$

where $\boldsymbol{\Sigma}_{\epsilon, i}$ is a $4 \mathrm{x} 4$ diagonal matrix with $\sigma_{\epsilon, k, i}^{2}$ as diagonal elements, for $k=0,1,2,3$, and $\sigma_{e_{i, t}}^{2}$ is given by equation (6).

Note that the timing of the model assumes that the right hand side variables are available at the beginning of period $t$ and this knowledge is used to make inferences about the left hand side variables. New observations for the left hand side variables become available at the end of each period $t$. The notation $t \mid t-1$ denotes usage of knowledge of period $t$ for the right hand variables and of period $t-1$ for the left hand side variables.

The first round of Kalman filter iterations estimates the model's hyperparameters 
$\left(\rho_{\pi, i}, \rho_{y, i}, \boldsymbol{\Sigma}_{\tilde{\boldsymbol{\epsilon}}, \boldsymbol{i}}\right)$. After estimating the hyperparameters, we run the Kalman filter for the second time in order to get an estimate for $\boldsymbol{\beta}_{\boldsymbol{i}, \boldsymbol{t}}$ from the first four rows of $\tilde{\boldsymbol{\beta}}_{\boldsymbol{i}, \boldsymbol{t}}$. The estimate of $\boldsymbol{\beta}_{\boldsymbol{i}, \boldsymbol{t}}$ is given correctly by iterating the Kalman filter as usually. However, given the two-step approach for solving the endogeneity issue and the usage of the control function, the standard errors of the coefficients face the problem of generated regressors (see Pagan, 1984). In our setting, while the true variance of $\boldsymbol{\beta}_{\boldsymbol{i}, \boldsymbol{t}}$ is calculated using the variance of $e_{i, t}, \boldsymbol{P}_{\boldsymbol{i}, \boldsymbol{t} \mid \boldsymbol{t}}$ is calculated using the variance of $\omega_{i, t}$, which is only a part of the variance of $e_{i, t}$. To address this issue, we follow Kim (2006) and augment the Kalman filter in order to get estimates for $\operatorname{Var}\left(\boldsymbol{\beta}_{\boldsymbol{i}, \boldsymbol{t}} \mid I_{t-1}\right)$ and $\operatorname{Var}\left(\boldsymbol{\beta}_{\boldsymbol{i}, \boldsymbol{t}} \mid I_{t}\right)$ from the first $4 \times 4$ block of $\boldsymbol{P}_{\boldsymbol{i}, \boldsymbol{t} \mid \boldsymbol{t}-\mathbf{1}}^{\boldsymbol{1}}$ and $\boldsymbol{P}_{i, t \mid t}^{*}$ :

$$
\begin{gathered}
\boldsymbol{P}_{\boldsymbol{i}, \boldsymbol{t} \mid \boldsymbol{t}-\mathbf{1}}^{*}=\mathbf{B} \boldsymbol{P}_{\boldsymbol{i}, \boldsymbol{t}-\mathbf{1} \mid \boldsymbol{t}-\mathbf{1}}^{*} \mathbf{B}^{\prime}+\boldsymbol{\Sigma}_{\tilde{\boldsymbol{\epsilon}}, \boldsymbol{i}}, \\
f_{i, t \mid t-1}^{*}=\tilde{\boldsymbol{X}}_{\mathbf{i}, \mathbf{t} \mid \mathbf{t}-\mathbf{1}}^{\prime} \boldsymbol{P}_{\boldsymbol{i}, \boldsymbol{t} \mid \boldsymbol{t}-\mathbf{1}} \tilde{\boldsymbol{X}}_{\boldsymbol{i}, \boldsymbol{t} \mid \boldsymbol{t}-\mathbf{1}}+\left(\rho_{\pi, i}^{2}+\rho_{y, i}^{2}\right)^{2} \sigma_{e_{i, t}}^{2} \\
\boldsymbol{P}_{\boldsymbol{i}, \boldsymbol{t} \mid \boldsymbol{t}}^{*}=\boldsymbol{P}_{\boldsymbol{i}, \boldsymbol{t} \mid \boldsymbol{t}-\mathbf{1}}-\boldsymbol{P}_{\boldsymbol{i}, \boldsymbol{t} \mid \boldsymbol{t}-\mathbf{1}} \tilde{\boldsymbol{X}}_{\boldsymbol{i}, \boldsymbol{t} \mid \boldsymbol{t}-\mathbf{1}} f_{i, t \mid t-1}^{*-1} \tilde{\boldsymbol{X}}_{\mathbf{i}, \mathbf{t} \mid \mathbf{t}-\mathbf{1}}^{\prime} \boldsymbol{P}_{\boldsymbol{i}, \boldsymbol{t} \mid \boldsymbol{t}-\mathbf{1}}
\end{gathered}
$$

\subsection{Stage B: Cointegration}

To examine whether the changes in conduct of monetary policy followed similar pattern across developed countries we concentrate on the analysis of the dependence between the estimated paths of coefficients. In particular, we want to know whether we can find a long-run cross-country relationship in the responses to inflation in the Taylor rules.

Our empirical methodology is dictated by the assumption of the unit root in the timevarying parameter representation of the monetary policy. Recall that the evolution of monetary policy is given by equation (7), so in order to study the existence of cross-country relationship between responses to inflation in Taylor rule, we have to take into account the non-stationary nature of the time-series in question.

Engle and Granger (1987) suggests that even though economic variables might be nonstationary there might exists a stable well-defined linear long-run relationship between these variables. If we define $\boldsymbol{\beta}_{\mathbf{1 , t}}=\left[\beta_{1,1, t}, \beta_{1,2, t}, \ldots, \beta_{1, k, t}\right]^{\prime}$ as a vector of responses to inflation in the Taylor rules in all the countries, then given equation (7) each element of $\boldsymbol{\beta}_{\mathbf{1}, \boldsymbol{t}}$ is $I(1)$. To 
study the existence of the commonality in the conduct of monetary policy we ask whether we can find a cointegrated relationship in $\boldsymbol{\beta}_{\mathbf{1}, \boldsymbol{t}}$, i.e. a vector $\boldsymbol{\xi}$ such that $\boldsymbol{\xi}^{\prime} \boldsymbol{\beta}_{\mathbf{1}, \boldsymbol{t}}$ is $I(0)$. If this is the case, we can say that there exists a "long-run" relationship in how monetary policy is conducted across countries. If such relation cannot be found we conclude that there does not exist a long-run common pattern in monetary policy response to inflation.

To test for cointegration we consider the $\operatorname{VAR}(1)$ representation of a $k \times 1$ vector $\boldsymbol{\beta}_{\mathbf{1}, \boldsymbol{t}}$. We choose to use one lag, taking into account equation (7) that shows how $\beta_{i, j, k}$ 's are generated. To test for the number of cointegrating relationships we follow the maximum eigenvalue and trace tests presented by Johansen and Juselius (1990) and Johansen (1991). ${ }^{18}$ The asymptotic distributions of the tests statistics are multivariate extensions of the DickeyFuller distributions and depend on a number of non-stationary components under the null hypothesis as well as on the presence of constant and/or trend.

In addition, since $\boldsymbol{\beta}_{1, t}$ are generated regressors, instead of using standard critical values, e.g. those presented in MacKinnon et al. (2000), we bootstrap the cointegration regression and simulate the distribution of Johansen statistics. Our approach is similar to that considered in Psaradakis (2001) and Chang et al. (2006) but, as far as we know, we are the first to adapt it to VAR-based cointegration test and the Johansen's statistics. The details of the bootstrap method can be found in Appendix B.2.

To study the robustness of our cointegration results given the uncertainty about timevarying parameter estimates, we apply this procedure also to the lower and upper $90 \%$ confidence band. ${ }^{19}$ Since the variances of estimates are time-varying themselves, the bands will not follow simply the estimates of $\boldsymbol{\beta}_{\mathbf{1}, \boldsymbol{t}}$.

\subsection{Principal Component Analysis}

Finally, we turn to studying the covariance structure of the shocks that affect the monetary policy feedback rules of the G7 countries. We do that in order to examine the possibility that common shocks are important, and might shadow the importance of common monetary policy response to inflation. Finding strong relationships in the covariance structure 
of the shocks of the Taylor rules is interpreted as common shocks being important for governing the G7 countries behavior. Given our reduced form modeling (necessary to reduce dimensionality), common components in the error terms of the Taylor rules is the natural place to look for commonality of shocks.

We use the principal component analysis in order to simplify the study of the sources of variation of our targeted covariance matrix. Specifically, we examine if we can identify a few linear combinations of the G7 Taylor rules shocks series that we generated in the first stage (the estimates of the series of $\omega_{i, t}$ 's in equation (23), with $i=1, \ldots, 7$ ), in order to examine the main components of variation of the covariance matrix that relates these series. Let $\omega_{\boldsymbol{t}} \equiv\left(\omega_{1, t}, \ldots, \omega_{7, t}\right)^{\prime}$ be the vector with the estimated shocks for the G7 countries at time $t$, and $\boldsymbol{\omega} \equiv\left(\boldsymbol{\omega}_{1}, \ldots, \boldsymbol{\omega}_{\boldsymbol{7}}\right)^{\prime}$ the matrix of the whole sample, with covariance matrix $\boldsymbol{\Sigma}_{\boldsymbol{\omega}}$. Through the principal component analysis we attempt to identify a few linear combinations of $\boldsymbol{\omega}_{\boldsymbol{i}}, i=1, \ldots, 7$, in order to understand the structure of $\boldsymbol{\Sigma}_{\boldsymbol{\omega}}$.

In Section 6.3 we compute the fraction of variation each principal component contributes towards. Having a small number of principal components contributing towards a large percentage of the variation of $\boldsymbol{\omega}$ makes the simplification of identifying the principal components useful. To estimate the optimal number of factors we use the Bai and $\mathrm{Ng}$ (2002) criterion.

\section{Data}

We use quarterly data for Canada, France, Germany, Italy, Japan, UK and US. For the European countries the sample stops on 1998:4. Data are taken from the Datastream database. We have data for short term interest rates, inflation and real Gross Domestic Product. ${ }^{20}$ We construct measures of interest rate spread and money growth to use as instrumental variables. ${ }^{21}$

We use annualized inflation rate constructed from the consumer price index. The consumer price indexes that were not originally seasonally adjusted (Canada, France, Italy, Japan, UK), were converted to seasonally adjusted series using the year-to-year percentage 
difference adjustment, similarly to Bullard and Singh (2008).

We also use annualized money growth, constructed from a money measure. ${ }^{22}$ We seasonally adjusted the money measures that were not originally adjusted (Italy, UK) using the year-to-year percentage difference adjustment. For most of the countries we used the M2 as a measure of money. For the UK we use Money and Quasi-money, which is the closest available series to the definition of M2. For Canada the M2 series is too short (starts in 1968) and we used the M1 instead. For France and Italy we did not use a money aggregate because the M2 starts in 1977 and end of 1975, respectively. For Italy we did not use interest rate spread either. The M2 series for Japan finishes at the beginning of 2008 .

We construct output gap as the deviation of seasonally adjusted log real GDP from the fitted quadratic trend. ${ }^{23}$ We finally construct interest rate spreads using the difference of a short term interest rate from a long term one. ${ }^{24}$

For the Taylor rules estimation we use a sample that is balanced within each country, but is not balanced across countries. Specifically, the balanced sample for the series used for each country is as follows: For Canada we use the sample period of 1961:2 - 2006:4, for France 1970:1 - 1998:4, for Germany 1969:2 - 1998:4, for Italy 1971:1 - 1998:4, for Japan 1966:4 - 2008:1, for UK 1965:2 - 2009:2 and for US 1960:2 - 2009:2. For examining cointegration and principal component analysis we adjust the sample and use effective sample 1976:2 - 1998:4.

\section{$6 \quad$ Empirical results}

We first report results from the estimations of individual countries' Taylor rules. Next we present results of tests that measure the commonality between coefficients across countries and analyze the covariance structure of the shocks.

\subsection{Taylor rule estimation results}

We report the estimated series of the the time varying coefficients for each country considered, with $90 \%$ confidence bands. Figures 4 through 10 depict that in all of the G7 
countries interest rate response to inflation is low during the 1970s (often at its lowest level), increases in the 1980s, and then, in countries with longer sample, we see that it decreases again after the mid 1990s.

\section{Insert Figures 4 and 5 HERE}

France's and Italy's responses to inflation, as shown in Figures 4 and 5, are low during the 1970s. The coefficients of interest increase and become higher than 1 only in the early 1980s. For France, this coefficient becomes statistically larger than 1 for some time during the 1980s, however, for Italy it is never statistically larger than 1. Given the introduction of the Euro in 1999 we do not have the sample to fully isolate the importance of inflation in the Taylor rule during the later period. However, the change in importance assigned to fighting inflation, from low during the 1970s to stronger during the 1980s, is apparent.

In Figure 6 we see that during the 1970s the coefficient of inflation for the UK is almost always significantly below 1. Similarly to the case of France, the estimated coefficient increases in the 1980s, and becomes significantly higher than 1. Having available longer sample than what we have for Italy and France, we observe that the response becomes less "aggressive" during the 1990s.

\section{Insert Figures 6 and 7 HERE}

For the US as we have longer sample available we can see more variation in the interest rate response to inflation. In Figure 7 we see strong response to inflation in the mid-1960s, which however becomes low during the 1970s. The response becomes again stronger and the coefficient is greater then 1 during the 1980s. Although not statistically different from 1, it decreases during the 1990s becomes even less than 1 in the late-1990s. This decreased response to inflation in the US during the 1990s has been previously reported by Kim et al. (2006) and Fernandez-Villaverde et al. (2010). Interestingly, we find evidence of decreased response of policy rate to inflation during the same period also for other countries.

Insert Figures 8 and 9 HERE 
In Figure 8 we see that the response to inflation for Germany is low during the 1970s and becomes statistically significantly higher than 1 at the beginning of the 1980 s. It also stays above 1 afterwards, although it is not statistically different than 1 in the later period. Contrary to the view that Germany had traditionally responded strongly to inflation and, as a consequence, did not experience high inflation during the 1970 s, our estimates suggest that the response to inflation was at its lowest during the 1970s. Moreover, as shown in Figure 2, Germany did get higher inflation during the 1970s compared to the previous and subsequent periods average. Earlier work has also documented that Germany accommodated inflation, similarly to the US, during the Great Inflation period (Clarida and Gertler, 1997). We find that the difference in monetary policies between Germany and the US is evident in how they responded to inflation during the 1990s rather than during the 1970s. Contrary to other developed countries, Germany remained aggressive in its response to inflation during the 1990s.

Similarly to the US a long sample is available for Canada. The nominal interest rate response to inflation, see Figure 9, is above 1 in the late 1960s and becomes lower than 1 during the 1970s. It increases to levels above 1 and remains statistically above 1 until the mid 1990s. This description matches the narrative evidence of Nelson (2005b). Canada's response to inflation starts decreasing after the mid 1990s, similarly to the US.

\section{Insert Figure 10 HERE}

Finally, Figure 10 shows Japan's time-varying response to inflation in the Taylor rule. Our estimated series show that Japan's response to inflation is low during the 1970s; however, it started to respond strongly to inflation slightly earlier than other countries, consistently with the narrative evidence of Nelson (2007). It remained above 1, although not statistically significant, until the beginning of the 1990s after which it decreased to values below 1. Our findings for Japan during the 1990s are not surprising given that during this period Japan hits the zero lower bound for the nominal interest rate.

If we consider the responses to inflation in all the countries considered we see the similar way that monetary authorities are changing their response to inflation over time, 
and especially in the period right before, during, and right after the Great Inflation era. We see from all countries a low response to inflation during the 1970s and much stronger during the 1980s and mid 1990s. This pattern could suggest that responding to inflation became less important during the 1990s, when inflation decreased and was under control. ${ }^{25}$ On the other hand, increased transparency, better understanding by public of monetary policy, and resulting gradual anchoring of inflation expectations could lead to a reduction of estimated responses. Moreover, as inflation becomes more stable (see Figure 2), it is harder to identify the response to inflation. ${ }^{26}$

The commonality of these pattern across all countries motivates us to investigate the possibility of a long run relationship among the series during and right after the Great Inflation period, presenting a cointegration test in the the next section.

\subsection{Cointegration analysis results}

In this subsection we present the results on the existence of cointergrating relationship between the inflation response series of the G7. Using estimated series of the time-varying coefficient in the Taylor rule for each country we conduct a cointegration analysis as described in Section 4.2. We look for a long-run relationship between the monetary policy responses to inflation in various countries, i.e., among the series of $\beta_{1, i, t}$ for the various countries $i$.

\section{Insert Table 2 HERE}

First, to verify that all series are I(1) we apply a Dickey-Fuller unit root test to each individual component of that vector. For each of the series we cannot reject the hypothesis of unit root at the $10 \%$ significance level. ${ }^{27}$ Results are presented in Table 2.

Next, we employ the Johansen procedure to find the number of cointegrating vectors. In Table 3 we show the results for Johansen's $\lambda_{\text {trace }}$ and $\lambda_{\max }$ tests for the case in which we exclude Japan. Given that the recession in Japan started in the early 1990s lasted past 1998:4 and brought both zero lower bound and unconventional monetary policy, the 
hypothesis that the monetary policy in Japan evolved differently from other G7 countries is justified.

\section{Insert Table 3 HERE}

For both tests, under the $H_{0}$ the rank of $\boldsymbol{\xi}$ is at least $r$ whereas under the alternative hypothesis, $H_{1}$, the rank is either strictly higher or equals $r+1$, respectively. We stress that since we estimate cointegration vectors using generated regressors, the asymptotic distributions of the Johansen statistics may not be valid. To correct for that we bootstrap the cointegrating regression and compute the relevant statistics. We repeat it for each possible null hypothesis.

At the $5 \%$ level, both tests reject the null hypothesis of no cointegration. In fact, once we exclude Japan, we find that we can reject the null hypothesis of 4 cointegrating vectors at 10\% level (and 3 cointegrating vectors at $5 \%$ level). These results strongly indicate the existence of 1 , or at most 2 , stochastic trends that describe the behavior of responses of monetary policy to inflation in G7 countries. This implies a very strong relationship in how the policy rate reacted to inflation among those six countries.

\section{Insert Table 4 HERE}

In addition, we test for cointegration the lower and upper confidence bands, see Table $4 .^{28}$ Note that since the estimates of the variance are time-varying themselves, the bands will not follow simply the estimates of coefficients on inflation. In general we find that there exists strong cointegrating relationship also in these cases: we find that there are five cointegrated relationships on the upper band and three on the lower band. This implies a unique stochastic trend that governs the behavior of upper bands in all six countries. The results for the lower bands are not as stark as for the upper band but still indicate high degree of connectedness.

We interpret the existence of cointegrating vectors as support for the existence of a long-run pattern in how the monetary policy is conducted in developed countries. While the changes in monetary policy may vary over time in different countries, there exists, 
nevertheless, commonality in the monetary policy implementation across countries in our sample.

\subsection{Principal Component Analysis results}

We now perform principal component analysis which allows us to study the covariance structure of the Taylor rules' innovations of the G7 countries. We interpret the cointegrated relationship of the coefficients as common policy, and the existence of strong principal components in the residuals, as common shocks.

\section{Insert Table 5 HERE}

Specifically, finding a small number of components driving a large percentage of variation would indicate that there are strong commonalities in the shocks structure of the G7 countries. On the contrary, finding that a large number of components is required in order to explain variation, would indicate that there is no strong commonality in the shocks' structure of the G7 countries. We perform the principal component analysis as summarized in Section 4.3. Table 5 reports the results for applying this analysis in the series of $\omega_{i, t}$ 's of equation (23). We see that the first component explains only $25.7 \%$, although we need four components in order to explain $73.4 \%$ of the residuals' variability. ${ }^{29}$ In addition, the efficient number of common factors as estimated using the information criterion of Bai and $\mathrm{Ng}$ (2002) is 7 . The results indicate that the shocks structure does not have a small number of principle components in order to approximate in a satisfactory extent the variability of the Taylor rules' residuals in various countries, with information of common components. Then, the variability of the G7 shocks seem to originate from multiple sources, with each having limited common effect. This observation decreases the importance of common shocks in our analysis.

In a related work, Chatterjee (2010) finds that individual countries' variation in the shocks of the Taylor rules is explained in a large extent by a common component, the G7 component. These results focus in the period after the Great Inflation, although we are interested in the period of the Great Inflation and after. Also, our analysis allows to study 
both the commonality in the shocks structure, but also the commonality in the monetary authorities' responses to inflation, focusing on the Great Inflation era. And we show, using the Taylor rule estimations and the cointegration tests, that there is an important common component in monetary policies response to inflation. Yet, the importance of common shocks is limited.

\section{Discussion}

In our analysis we have employed sophisticated econometric techniques in oder to correctly identify the time varying coefficients. However, given that we use a reduced form econo-

metric model, there is the possibility of model misspecification. In order to support our argument about common policy around the developed world, we recur and discuss narrative evidence provided by previous research. ${ }^{30}$

For the US, Romer and Romer (2002, 004) and Romer (2005) use narrative evidence and argue that during the 1950s and after the 1980s monetary authorities were using models of the economy that allowed them to control inflation. These models were attributing high cost to inflation and were lacking the long-run tradeoff between inflation and unemployment. On the contrary, during the 1960s and 1970s, monetary authorities were operating using economic models implying that inflation is a cost-push phenomenon, or/ and perceived a low natural unemployment rate, discouraging them from controlling inflation. Similar line of reasoning is also present in Sargent (1999), Cogley and Sargent (2005) and Sargent et al. (2006). Additionally, Romer and Romer (2002) find that the Greenbook forecasts were greatly underestimating inflation during the Great Inflation period, revealing the possibility of flaws in the models used.

Moreover, Nelson (2005a) proposes the monetary neglect hypothesis, according to which the Great Inflation was the result of monetary authorities attributing inflation during the 1970s to a set of non-monetary reasons. Narrative evidence indicates that inflation was believed to be a cost-push, instead of monetary phenomenon, and that the monetary authority was unable to influence monetary variables that affect the real economy. In a series of pa- 
pers, Nelson shows that the monetary neglect hypothesis is supported by the experience in other developed countries, indicating a common cause of inflation, i.e., the departure of the idea that inflation is connected to monetary policy.

In particular, Nelson (2005b) argues that Canada's narrative evidence reveals accommodative policy during the 1970s, following non-monetary reasoning. Switching to tighter policy by late 1978 was the result of a belief that inflation increases because of expensive imported goods. Canada's authorities tried to avoid further exchange rate depreciation, using monetary ways. Nelson (2007) observes that Germany and Japan experienced inflationary spikes earlier than other countries, and their inflationary periods were shorter. He argues that this pattern fits the monetary neglect hypothesis and both Germany and Japan experienced early disinflation because they abandoned quickly the non-monetary ideas about inflation. For the UK, DiCecio and Nelson (2009) present narrative evidence that suggests various switches between accommodative and tight policy. They identify, as the most important switch, the election of Margaret Thatcher in 1979, after which many non-monetary behaviors diminished and tight monetary policy as a response to high inflation was introduced.

Romer (2005) claims that the international experience, captured in Figure 1, suggests that the common behavior in the inflation pattern of the G7 countries implies common monetary policy behavior: common ideas gave rise to inflation during the 1970s, and improved common ideas motivated policy makers to combat inflation during the 1980s. Romer (2005) argues that ideas spread around the world as monetary economists share their views through conferences, books and research papers. Then, countries that differ in their fiscal stance and economic conditions followed commonly accommodative policies during the 1970s, and although switching at different points in time, commonly tight policies, after the beginning of the 1980s. 


\section{Conclusions}

We employ a multi-country analysis of monetary policy using a time-varying, forwardlooking Taylor rule. We find that in the G7 countries the interest rate responses to inflation follow similar pattern: all countries react mildly during the 1970s and aggressively from the 1980s until the mid-1990s. In addition, our analysis of cointegration indicates that whereas the changes in monetary policy may vary over time in individual countries, there exists, nevertheless, commonality in the monetary policy implementation across the G7 countries during the Great Inflation period. Narrative evidence supports these findings too. On the contrary, the principal component analysis reveals many sources of variation rather than one strong common component in the shocks' structure. We interpret the common pattern revealed by the Taylor rule estimations and the findings of cointegrated relationship of the coefficients, as evidence of common policy.

Future work mandates addressing Orphanides (2002)'s critique, which emphasizes the effects that the potential output mis-measurement has in Taylor rule estimations. This explanation could be robust with the international evidence if for example we consider that the knowledge about output gap calculations was shared among economists around the world, and they might have all been using methods that led to mis-measurement errors. Boivin (2006), Kim et al. (2006) and Nikolsko-Rzhevskyy and Papell (2012) take this critique into account and use real time data for the US. Yet, their work still concludes that monetary authorities responded milder to inflation during the 1970s and, for the first two papers, stronger after that. Our analysis provides evidence in favor of common monetary

policy rather than common shocks as an explanation of the common inflation patterns in the G7 countries. However, more work on the topic is required for addressing the above issue. 


\section{Notes}

${ }^{1}$ Previous work, using a different model that estimates Philips Curves in the G7 countries, finds that trend inflation is at its highest during the 1970s in the G7 countries (Morley et al., 2015). Note that trend inflation is related to long run expectations that the central banks may influence.

${ }^{2}$ Blinder (1982) argues that the oil price shocks are responsible for the inflation pattern observed during the 1970s. Meltzer (2005) suggests an explanation based on the coordination of the Federal Reserve System with the Treasury. He argues that although the monetary authorities were aware of the too high inflation they could not react due to political pressure. He points out that the Great Inflation started when the coordination of monetary policy become necessary for the government and ended when the Federal Reserve became independent.

${ }^{3}$ Lubik and Schorfheide (2004) estimate a DSGE New-Keynesian model and find that monetary policy was indeterminate at the pre-Volker era. Mavroeidis (2010) finds that identification is possible for this early part of the sample, and verifies Clarida, Galí, and Gertler (2000) results.

${ }^{4}$ Similarly, Sargent (1999) and Cogley and Sargent (2005) consider the argument that the Great Inflation was promoted by the monetary authorities changing views about the natural rate hypothesis. Nelson (2005a,b) propose the monetary neglect hypothesis according to which the Great Inflation was the result of monetary authorities attributing inflation to non-monetary reasons during the 1970s.

${ }^{5}$ Additionally, the timing of the Great Inflation in other countries does not correlate with their central banks' independence, and thus monetary authorities' independence does not seem to be the reason behind the international Great Inflation. For example, Bundesbank was an independent bank from very early on, and the Banque de France, Bank of England and Bank of Japan became independent during the 1990s, when inflation had already leveled off.

${ }^{6}$ Note that we are interested in evaluating commonalities in the interest rate responses to inflation and not in the level of interest rates, per se. FAVAR models (e.g., Mumtaz and Surico, 2009) would be useful in pursuing the latter route.

${ }^{7}$ Examples of such perceptions are the permanent trade-off between inflation and unemployment and monetary policy's ineffectiveness towards cost-push inflation.

${ }^{8}$ We use that date as most of the G7 experienced a significant change around that period. Thatcher took office in the UK after May 1979, the European counties entered the European Monetary System on March 1979 and Volker took office in the Federal Reserve on August 1979. Our approach and results are consistent with those in Clarida et al. (1998).

${ }^{9}$ We use lagged values of output gap, inflation, interest rates, M2 money growth, and spread between long and short term interest rates as instruments.

${ }^{10}$ Among many others, Nelson (2005b) has used interest rate rules for Canada, Bullard and Singh (2008) 
for Germany and Japan, DiCecio and Nelson (2009) for UK and Clarida et al. (2000) and Sims and Zha (2006) for the US.

${ }^{11}$ Multi-country models that do not have to deal with this issue (as for example in Canova and Ciccarelli, 2009), avoid the extra complexity that endogeneity requires, and add complexity in other parts of the model.

${ }^{12}$ The full model would include the joint estimation of the time varying parameter model for all G7 countries, addressing endogeneity, heteroskedasticity, and nonlinearity.

${ }^{13}$ Creel and Hubert (2015) discuss relative merits of three alternative econometric models - structural break model, a time-varying parameter model with stochastic volatility, and a Markov-switching VAR models - when studying changes in the Taylor rule and the conduct of monetary policy.

${ }^{14}$ Kim and Nelson (2006) used this framework for estimating a monetary policy rule for the United States while Kishor (2012) used it for France, Germany, Italy, and the United Kingdom.

${ }^{15}$ This is true even for i.i.d. disturbances $v_{\nu, i, t}$, given the time-varying parameter framework. See Kim and Nelson (2006) for further discussion.

${ }^{16}$ As Kim (2006) noted, Kalman filter needs to be augmented to allow for correct conditional variance of $\beta_{t}$, see Section 4.1 for details.

${ }^{17}$ When there is no time variation in the parameters, as for example in Clarida et al. (2000), it is enough to divide with $(1-\theta)$. However, here, due to time variation in the smoothing parameter, this is not possible. That is why we proceed with linearization.

${ }^{18}$ See also Johansen (1995) for details.

${ }^{19}$ That is, we check for cointegration for the series $\hat{\boldsymbol{\beta}}_{1, t} \pm 1.65 \times \widehat{\boldsymbol{v a r}}_{t}\left(\hat{\boldsymbol{\beta}}_{1, t}\right)$.

${ }^{20}$ Series that are available monthly are converted to quarterly using the value of the first month of each quarter. These series are the CPI for Germany and for US. For France and Germany we construct real GDP using the nominal one and CPI. For Japan, we used the nominal GDP and the GDP deflator.

${ }^{21}$ For policy instruments we use: For Canada the three-month treasury bill rate (similarly to Nelson, 2005b); for France the call money rate; for Germany the interbank money rate (similarly to Bullard and Singh, 2008); for Italy the money market rate (which is the three-month interbank rate before February 1990, after which becomes the daily rate); for Japan the money market rate for overnight loans (similarly to Bullard and Singh, 2008); for UK the treasury bill rate (similarly to DiCecio and Nelson, 2009); for the US the Federal Funds Rate (similarly to Bullard and Singh, 2008).

${ }^{22}$ Annualized money growth rate at time $t=\left(\frac{M_{t}-M_{t-1}}{M_{t-1}}\right) 400 \%$. Also, annualized inflation rate at time $t=\left(\frac{C P I_{t}-C P I_{t-1}}{C P I_{t-1}}\right) 400 \%$.

${ }^{23}$ For log real GDP being $g d p_{t}$, then we fit $g d p_{t}=j_{0}+j_{1} t+j_{2} t^{2}+s_{t}$, and construct the gap as $y_{t}=g d p-\overline{g d p}$, for $\overline{g d p}=j_{0}+j_{1} t+j_{2} t^{2}$, for the estimates of $j_{1}, j_{2}$ computed above, and $t$ being the time trend.

${ }^{24}$ For constructing the spread we use: For Canada the more than 10-year government bond yield and the 3 to 5 -year government bond yield (the Treasury bill serves as policy instrument); for France the more 
than 5-year government bond yield, and the Treasury bill rate (the 12-month treasury bills until June 1989 and the 3-month Treasury bills after that); for Germany the long term government bond yield and the call money market rate (the Treasury bill rate becomes available only after the third quarter of 1975); for Italy we use the the long term government bond yield and the discount rate (the Treasury bill rate starts much later, in 1977); for Japan the long term government bond yield and the Japan Treasury bill rate; for UK we use the 20-year government bond yield and the 5-year government bond yield (the Treasury bill serves as policy instrument); for the US the 10-year US government bond yield and 3-month US Treasury bill rate.

${ }^{25}$ Such an observation would be consistent with Taylor (2007)'s claim that the US monetary policy was very accommodative in years 2003-2005.

${ }^{26}$ This is why the confidence bands often become wider, as it also happens at Kim and Nelson (2006) (see the explanation at the page 1958 and their Figure 2).

${ }^{27}$ While we postulated a unit root in the $\beta$ specifying the nature of the time variation of the coefficients, such specification is general enough that if true $\beta$ was stationary, the estimated coefficients would be also stationary. We apply Augmented Dickey-Fuller tests to confirm that there are, indeed, unit roots in the estimated series and our subsequent cointegration analysis is valid. In case of Japan we only marginally accept null hypothesis of unit root at $10 \%$ for $\mathrm{ADF}$ regression with 2 lags.

${ }^{28}$ We present only results for $\lambda_{\text {trace }}$ but results for $\lambda_{\max }$ are available upon request.

${ }^{29}$ As a comparison, Tsay (2010) page 487 finds in a different application, that the first component explains $53.5 \%$ of total volatility which is much larger than the volatility our first principal component explains. In addition, Tsay (2010) uses two components out of five series (which is $40 \%$ of available components) for explaining cumulatively $74 \%$ of total volatility. In our case, we need almost $60 \%$ of available components in order to explain almost the same fraction of volatility.

${ }^{30}$ We very much thank a referee for suggesting including this evidence. 


\section{References}

Bai, J. and S. Ng (2002). Determining the number of factors in approximate factor models. Econometrica $70(1), 191-221$.

Baxa, J., R. Horvth, and B. Vacek (2014). How does monetary policy change? evidence on inflation-targeting countries. Macroeconomic Dynamics 18(3), 593-630.

Blinder, A. S. (1982). The anatomy of double-digit inflation in the 1970s, in Hall, R. E. (Ed.), Inflation: Causes and Effects, NBER, 261-282. University of Chicago Press.

Boivin, J. (2006). Has U.S. monetary policy changed? Evidence from drifting coefficients and real-time data. Journal of Money, Credit and Banking 38(5), 1149-1173.

Bullard, J. and A. Singh (2008). Worldwide macroeconomic stability and monetary policy rules. Journal of Monetary Economics 55(1), 34-47.

Canova, F. and M. Ciccarelli (2009). Estimating multicountry VAR models. International Economic Review 50(3), 929-959.

Chang, Y., J. Y. Park, and K. Song (2006). Bootstrapping cointegrating regressions. Journal of Econometrics 133(2), 703-739.

Chatterjee, A. (2010). Globalization and monetary policy: An empirical analysis. Unpublished Manuscript, University of New South Wales.

Clarida, R., J. Galí, and M. Gertler (1998). Monetary policy rules in practice. some international evidence. European Economic Review 42, 1033-1067.

Clarida, R., J. Galí, and M. Gertler (2000). Monetary policy rules and macroeconomic stability: Evidence and some theory. The Quarterly Journal of Economics 115(1), 147180.

Clarida, R. and M. Gertler (1997). How the Bundesbank conducts monetary policy, in Romer, C. D. and Romer, D. H. (Ed.) Reducing Inflation: Motivation and Strategy, NBER, 363-412. University of Chicago Press. 
Cogley, T. and T. J. Sargent (2005). The conquest of US inflation: Learning and robustness to model uncertainty. Review of Economic Dynamics 8(2), 528-563.

Creel, J. and P. Hubert (2015). Has inflation targeting changed the conduct of monetary policy? Macroeconomic Dynamics 19(1), 1-21.

DeLong, B. J. (1997). America's Peacetime Inflation: The 1970's, in Romer, C. D. and Romer, D. H. (Ed.), Reducing Inflation: Motivation and Strategy, 247-276. University of Chicago Press.

DiCecio, R. and E. Nelson (2009). The Great Inflation in the United States and the United Kingdom: Reconciling policy decisions and data outcomes. Federal Reserve Bank of St. Louis Working Papers (015-B).

Engle, R. and C. Granger (1987). Co-integration and error correction: Representation, estimation, and testing. Econometrica 55(2), 251-76.

Fernandez-Villaverde, J., P. A. Guerron, and J. F. Rubio-Ramirez (2010). Reading the recent monetary history of the United States, 1959-2007. Federal Reserve Bank of St. Louis Review 92(4), 311-338.

Friedman, M. and G. Allen (16 September, 1970). The Counter-revolution in Monetary Theory: First Wincott Memorial Lecture Delivered at the Senate House, University of London. Institute of Economic Affairs.

Goodfriend, M. (1991). Interest rates and the conduct of monetary policy. In CarnegieRochester conference series on public policy. North-Holland 34, 7-30.

Guerron, P. A. (2013). Common and idiosyncratic disturbances in developed small open economies. Journal of International Economics 90(1), 33-49.

Johansen, S. (1991). Estimation and hypothesis testing of cointegration vectors in Gaussian vector autoregressive models. Econometrica 59(6), 1551-1580. 
Johansen, S. (1995). Likelihood-based inference in cointegrated vector autoregressive models. Oxford University Press.

Johansen, S. and K. Juselius (1990). Maximum likelihood estimation and inference on cointegration-with applications to the demand for money. Oxford Bulletin of Economics and Statistics 55(2), 169-210.

Kim, C.-J. (2006). Time-varying parameter models with endogenous regressors. Economics Letters $91(1), 21-26$.

Kim, C.-J. (2008). Dealing with endogeneity in regression models with dynamic coefficients. Foundations and Trends in Econometrics 3(3), 1-88.

Kim, C.-J., K. Kishor, and C. R. Nelson (2006). A time-varying parameter model for a forward-looking monetary policy rule based on real-time data. University of Washington Working Paper UWEC-2007-32.

Kim, C.-J. and C. R. Nelson (1989). The time-varying-parameter model for modeling changing conditional variance: The case of the Lucas hypothesis. Journal of Business $\mathscr{E}$ Economic Statistics 7(4), 433-40.

Kim, C.-J. and C. R. Nelson (2006). Estimation of a forward-looking monetary policy rule: A time-varying parameter model using ex post data. Journal of Monetary Economics 53(8), 1949-1966.

Kishor, N. K. (2012). A note on time variation in a forward-looking monetary policy rule: evidence from European countries? Macroeconomic Dynamics 16(S3), 422-437.

Kose, A., C. Otrok, and C. H. Whiteman (2003). International business cycles: World, region, and country-specific factors. American Economic Review 93(4), 1216-1239.

Lubik, T. A. and F. Schorfheide (2004). Testing for indeterminacy: An application to U.S. monetary policy. American Economic Review 94(1), 190-217. 
MacKinnon, J. G., A. Haug, and L. Michelis (2000). European Monetary Union: a cointegration analysis. Journal of International Money and Finance 19(3), 419-432.

Mavroeidis, S. (2010). Monetary policy rules and macroeconomic stability: some new evidence. The American Economic Review 100(1), 491-503.

Meltzer, A. H. (2005). Origins of the Great Inflation. Federal Reserve Bank of St. Louis Review 87(2), 145-176.

Morley, J., J. Piger, and R. Rasche (2015). Inflation in the G7: Mind the gap(s)? Macroeconomic Dynamics, 1-30.

Mumtaz, H. and P. Surico (2009). The transmission of international shocks: A factoraugmented VAR approach. Journal of Money, Credit and Banking 41(1), 71-100.

Nelson, E. (2005a). The Great Inflation of the seventies: What really happened? Advances in Macroeconomics 5(1), 1297-1297.

Nelson, E. (2005b). Monetary policy neglect and the Great Inflation in Canada, Australia and New Zealand. International Journal of Central Banking 1(1), 133-179.

Nelson, E. (2007). The Great Inflation and early disinflation in Japan and Germany. International Journal of Central Banking 3(4), 23-76.

Nikolsko-Rzhevskyy, A. and D. Papell (2012). Taylor rules and the great inflation. Journal of Macroeconomics 34(4), 903-918.

Orphanides, A. (2002). Monetary-policy rules and the great inflation. American Economic Review 92(2), 115-120.

Pagan, A. R. (1984). Econometric issues in the analysis of regressions with generated regressors. International Economic Review 25(1), 221-47.

Primiceri, G. (2005). Time varying structural vector autoregressions and monetary policy. Review of Economic Studies 72(1), 821-852. 
Psaradakis, Z. (2001). On bootstrap inference in cointegrating regressions. Economics Letters 72(1), 1-10.

Romer, C. D. (2005). Commentary on "Origins of the Great Inflation". Federal Reserve Bank od St. Louis Review 87(2), 177-186.

Romer, C. D. and D. H. Romer (2002). A rehabilitation of monetary policy in the 1950s. American Economic Review 92(2), 121-127.

Romer, C. D. and D. H. Romer (2004). Choosing the federal reserve chair: Lessons from history. Journal of Economic Perspectives 18(1), 129-162.

Sargent, T., N. Williams, and T. Zha (2006). Shocks and government beliefs: The rise and fall of American inflation. American Economic Review 96(4), 1193-1224.

Sargent, T. J. (1999). The Conquest of American inflation. Princeton University Press.

Sims, C. and T. Zha (2006). Were there regime switches in U.S. monetary policy? American Economic Review 96(1), 54-81.

Taylor, J. (2007). Housing and monetary policy. Proceedings - Economic Policy Symposium - Jackson Hole, 463-476.

Tsay, R. S. (2010). Analysis of financial time series. Wiley Series in Probability and Statistics. 


\section{Tables}

Table 1: Split sample estimates of $\beta_{\mathbf{1}}$

\begin{tabular}{ccc}
\hline Country & pre-1979:2 & post-1979:3 \\
\hline \hline$\beta_{1, C A N}$ & 0.642 & 0.916 \\
& $(0.29)$ & $(0.47)$ \\
$\beta_{1, F R A}$ & 0.342 & 0.977 \\
& $(0.33)$ & $(0.27)$ \\
$\beta_{1, G E R}$ & 0.230 & 1.269 \\
& $(0.35)$ & $(0.35)$ \\
$\beta_{1, I T A}$ & 0.538 & 0.870 \\
& $(0.13)$ & $(0.13)$ \\
$\beta_{1, J A P}$ & 0.498 & 1.642 \\
& $(0.07)$ & $(0.26)$ \\
$\beta_{1, U K}$ & -0.265 & 1.060 \\
& $(0.31)$ & $(0.21)$ \\
$\beta_{1, U S}$ & 0.478 & 1.353 \\
& $(0.09)$ & $(0.35)$ \\
\hline \hline
\end{tabular}

Note: Estimates from the simple Taylor rule (1) using all the available data for each country, splitting the sample in two: until 1979:2 and after 1979:3. Standard errors in parentheses.

Table 2: Augmented Dickey-Fuller (unit root) test of $\beta_{\mathbf{1}}$

\begin{tabular}{cccc}
\hline Country & t-statistics & p-value & p-value $_{A I C}$ \\
\hline \hline$\beta_{1, C A N}$ & -0.423 & 0.528 & 0.622 \\
$\beta_{1, F R A}$ & -0.273 & 0.586 & 0.241 \\
$\beta_{1, G E R}$ & -1.093 & 0.247 & 0.427 \\
$\beta_{1, I T A}$ & 0.791 & 0.882 & 0.882 \\
$\beta_{1, J A P}$ & -1.170 & 0.219 & 0.105 \\
$\beta_{1, U K}$ & -0.131 & 0.637 & 0.681 \\
$\beta_{1, U S}$ & -0.721 & 0.403 & 0.447 \\
\hline \hline
\end{tabular}

Note: $t$-statistics computed for 0 lags. $p$-value ${ }_{0}$ computed for 0 lags and $p$-value AIC $_{\text {computed for }}$ optimal number lags according to AIC, both based on MacKinnon (1996). 
Table 3: Johansen's trace and maximum eigenvalue tests for cointegration for 6 countries, no Japan.

\begin{tabular}{c||ccc|ccc}
\hline$H_{0}$ & $H_{1}^{\text {trace }}$ & $\lambda_{\text {trace }}$ & $p$-value trace & $H_{1}^{\max }$ & $\lambda_{\max }$ & $p$-value $\max$ \\
\hline \hline$r=0$ & $r \geq 0$ & $197.21^{* * *}$ & 0.002 & $r=1$ & $83.42^{* * *}$ & 0.008 \\
$r \leq 1$ & $r \geq 2$ & 113.78 & 0.193 & $r=2$ & 40.95 & 0.645 \\
$r \leq 2$ & $r \geq 3$ & $72.83^{* *}$ & 0.054 & $r=3$ & 32.90 & 0.25 \\
$r \leq 3$ & $r \geq 4$ & $39.93^{* *}$ & 0.019 & $r=4$ & $24.56^{* *}$ & 0.023 \\
$r \leq 4$ & $r \geq 5$ & $15.37^{*}$ & 0.052 & $r=5$ & 9.19 & 0.182 \\
$r \leq 5$ & $r \geq 6$ & 6.18 & & $r=6$ & 6.18 & \\
\hline
\end{tabular}

Note: $p$ - values based on bootstrapped regression. Specification: $\operatorname{VAR}(1)$ in levels, no drift, no trend. Constant in cointegrating relationship.

Table 4: Johansen's trace and maximum eigenvalue tests for cointegration for the lower and upper bands (5\% level) for 6 countries, no Japan.

\begin{tabular}{c|c||cc|cc}
\hline \multirow{2}{*}{$H_{0}$} & \multirow{2}{*}{$H_{1}^{\text {trace }}$} & \multicolumn{2}{c|}{ Upper band } & \multicolumn{2}{c}{ Lower band } \\
\cline { 3 - 6 } & $\lambda_{\text {trace }}$ & $p$-value & trace & $\lambda_{\text {trace }}$ & p-value \\
trace \\
\hline \hline$r=0$ & $r \geq 0$ & $222.74^{* * *}$ & 0.001 & $233.29^{* * *}$ & 0.001 \\
$r \leq 1$ & $r \geq 2$ & $146.53^{* * *}$ & 0.008 & $128.68^{* *}$ & 0.023 \\
$r \leq 2$ & $r \geq 3$ & $76.23^{* *}$ & 0.027 & 45.02 & 0.79 \\
$r \leq 3$ & $r \geq 4$ & $42.23^{* * *}$ & 0.008 & 23.58 & 0.53 \\
$r \leq 4$ & $r \geq 5$ & $22.64^{* * *}$ & 0.007 & 9.17 & 0.59 \\
$r \leq 5$ & $r \geq 6$ & 6.35 & & 3.54 & \\
\hline
\end{tabular}

NotE: $p$ - values based on bootstrapped regression. Specification: VAR(1) in levels, no drift, no trend. Constant in cointegrating relationship.

Table 5: Principle Component Analysis

\begin{tabular}{c||ccccccc}
\hline & Comp 1 & Comp 2 & Comp 3 & Comp 4 & Comp 5 & Comp 6 & Comp 7 \\
& & & & & & & \\
\hline \hline Eigenvalue & 1.803 & 1.447 & 1.040 & 0.854 & 0.741 & 0.622 & 0.494 \\
Proportion & 0.257 & 0.206 & 0.149 & 0.122 & 0.106 & 0.089 & 0.071 \\
Cumulative Proportion & 0.257 & 0.463 & 0.612 & 0.734 & 0.840 & 0.929 & 1 \\
\hline
\end{tabular}

Note: Principle Component Analysis in the series of residuals $\left(\omega_{i, t}\right)$ of the Taylor rule equation (23), for $i$ being Canada, France, Germany, Italy, Japan, US and UK, for the sample 1976:2 to 1998:4.

\section{Figures}




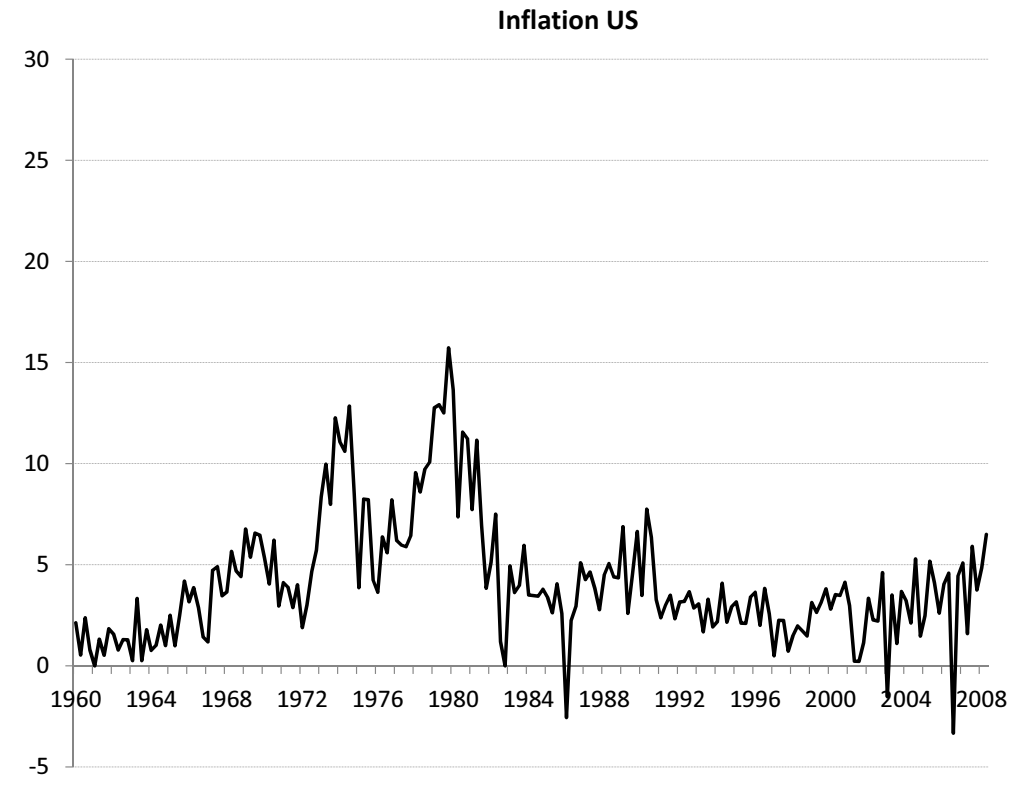

Figure 1: CPI Inflation rate for the USA, quarterly, seasonally adjusted data.
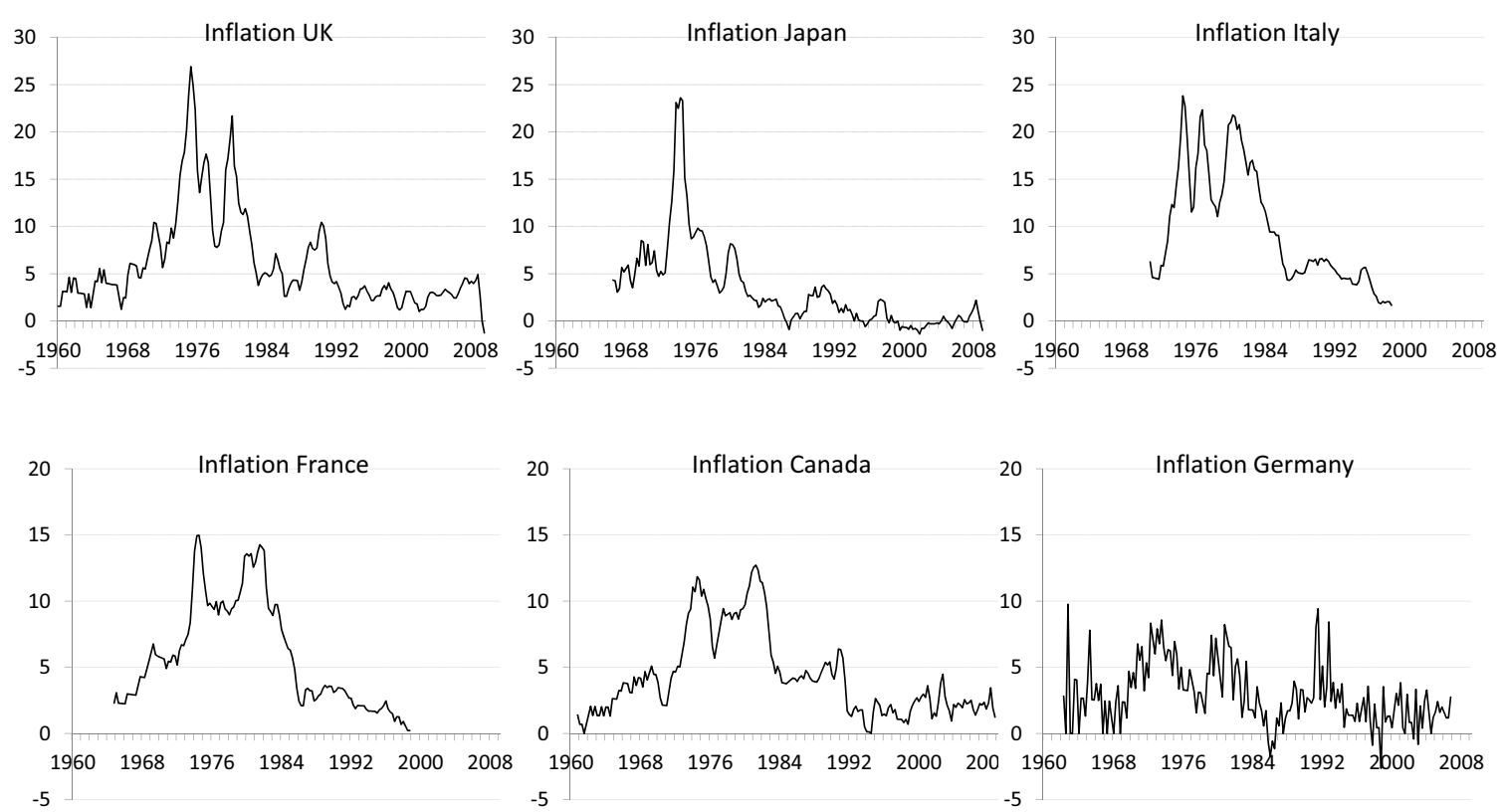

Figure 2: CPI Inflation in the G7 countries 

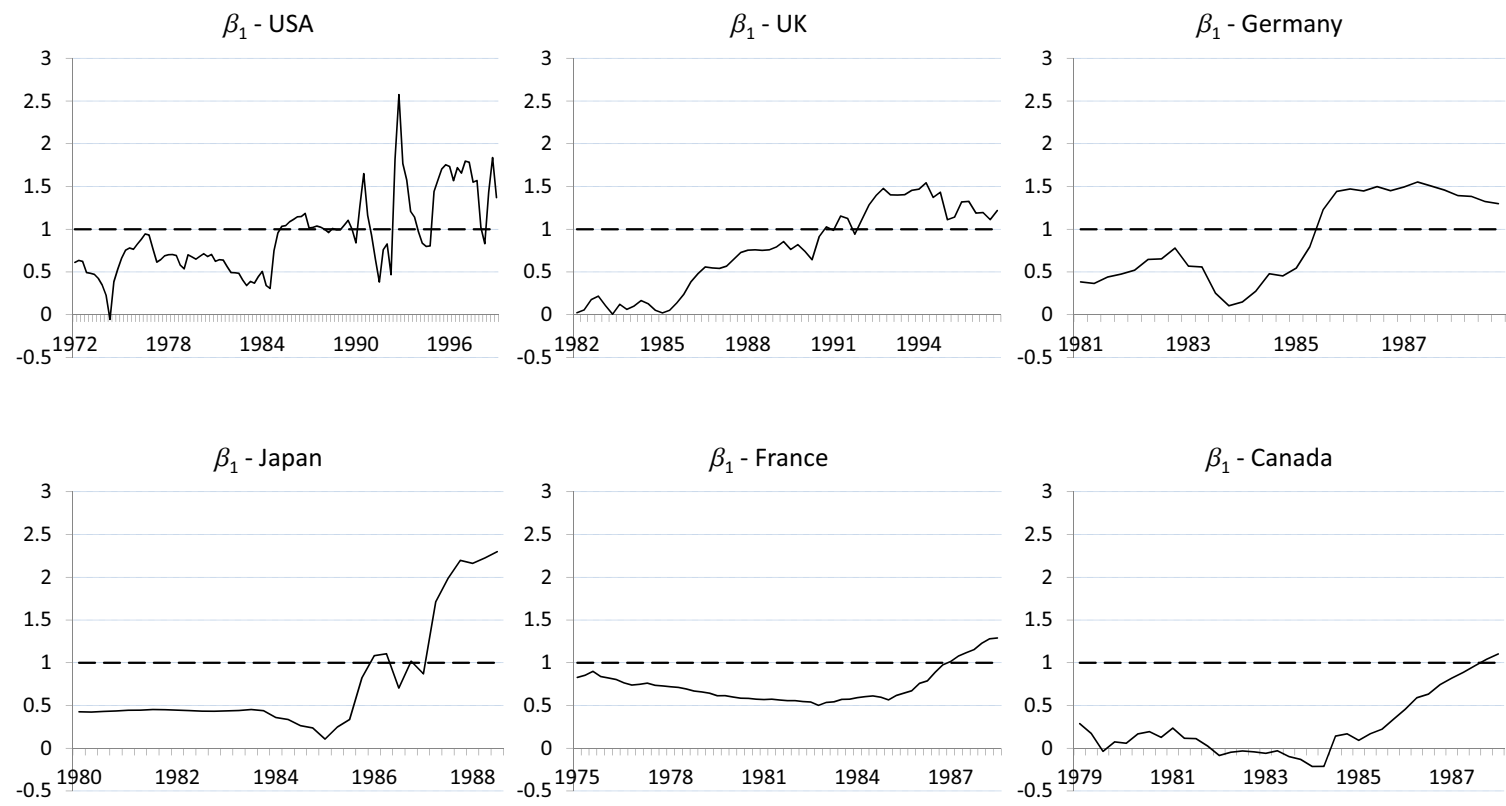

Figure 3: Rolling sample estimates of the coefficients of inflation, for 80 periods window. For example, the 1979 third quarter point refers to the estimate for the period 1969 third quarter to 1989 third quarter.

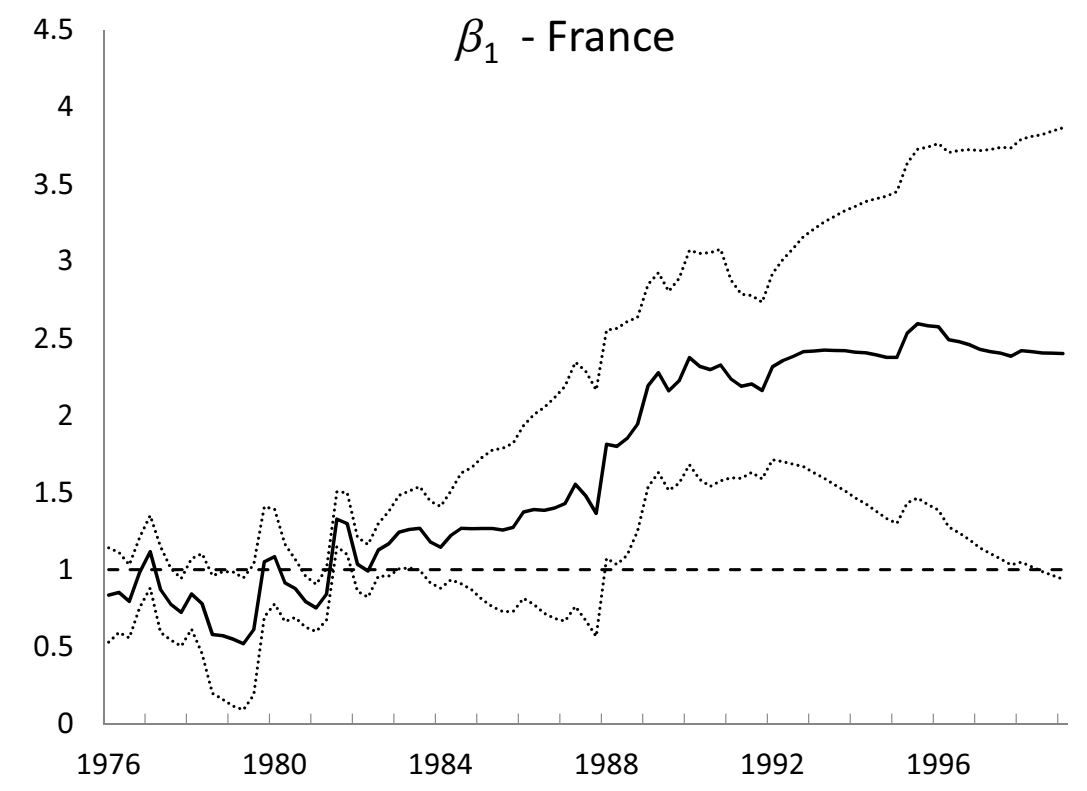

Figure 4: Estimated time varying response to inflation in France (solid line), and 90\% confidence bands (doted lines). The dashed line indicates the value 1 . 


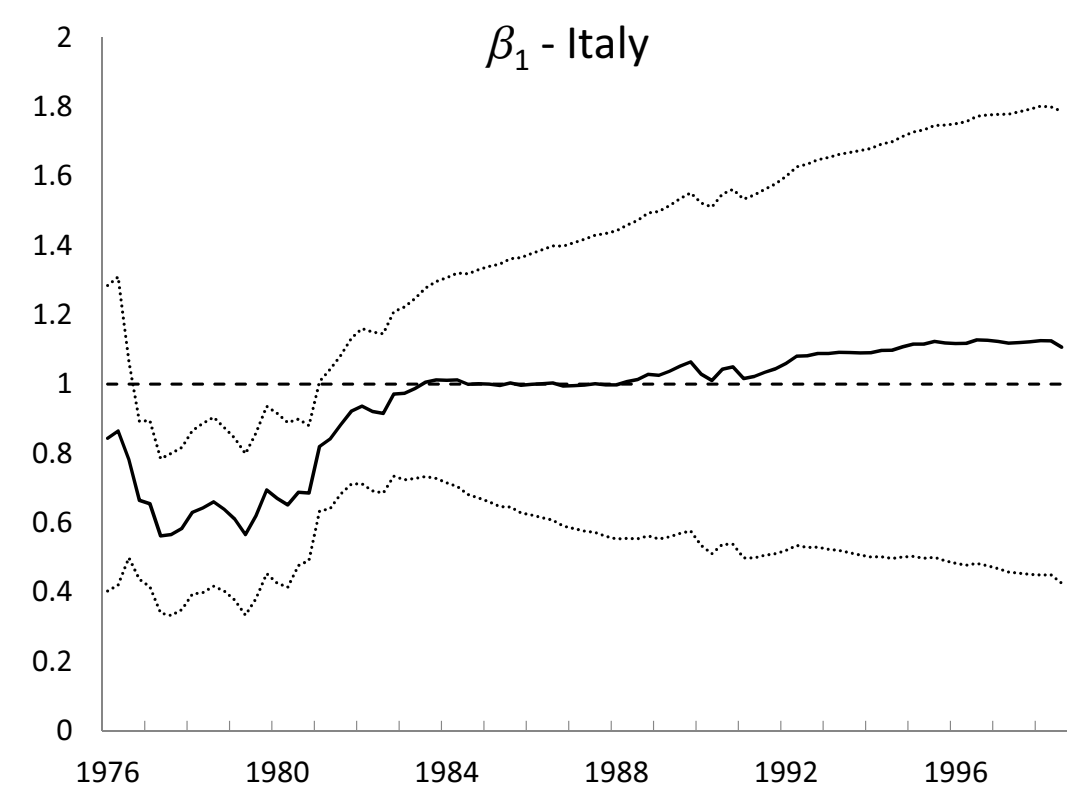

Figure 5: Estimated time varying response to inflation in Italy (solid line), and $90 \%$ confidence bands (doted lines). The dashed line indicates the value 1.

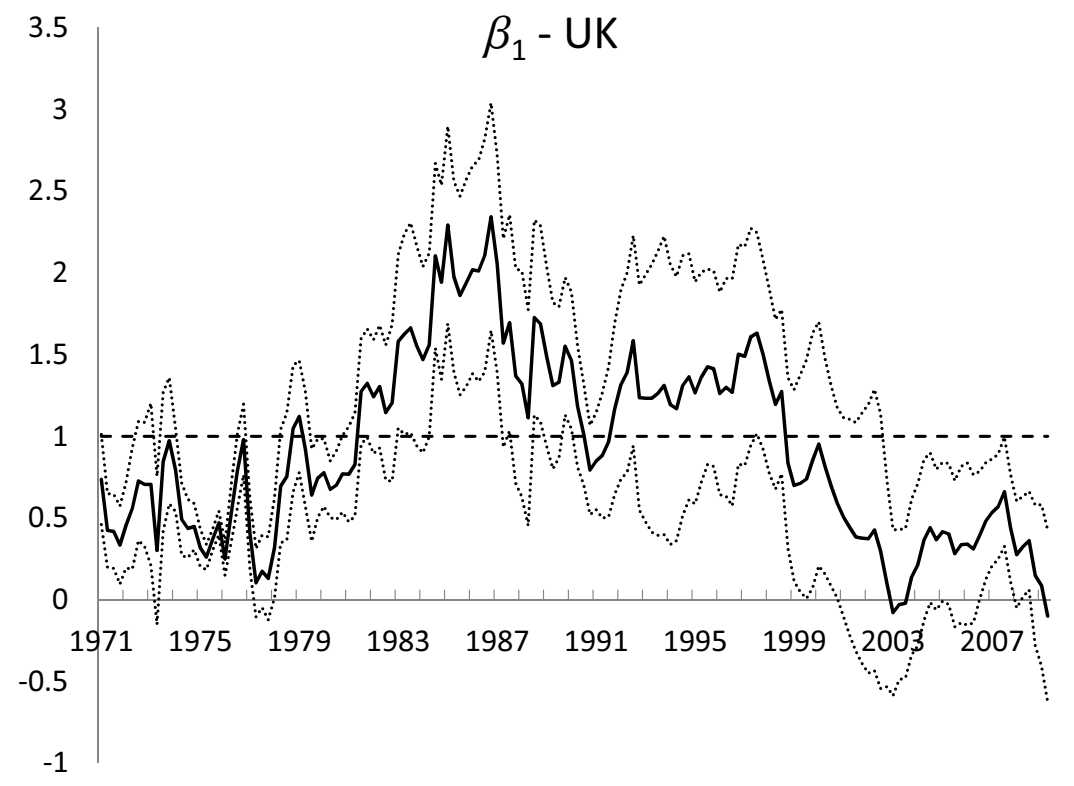

Figure 6: Estimated time varying response to inflation in UK (solid line), and $90 \%$ confidence bands (doted lines). The dashed line indicates the value 1 . 


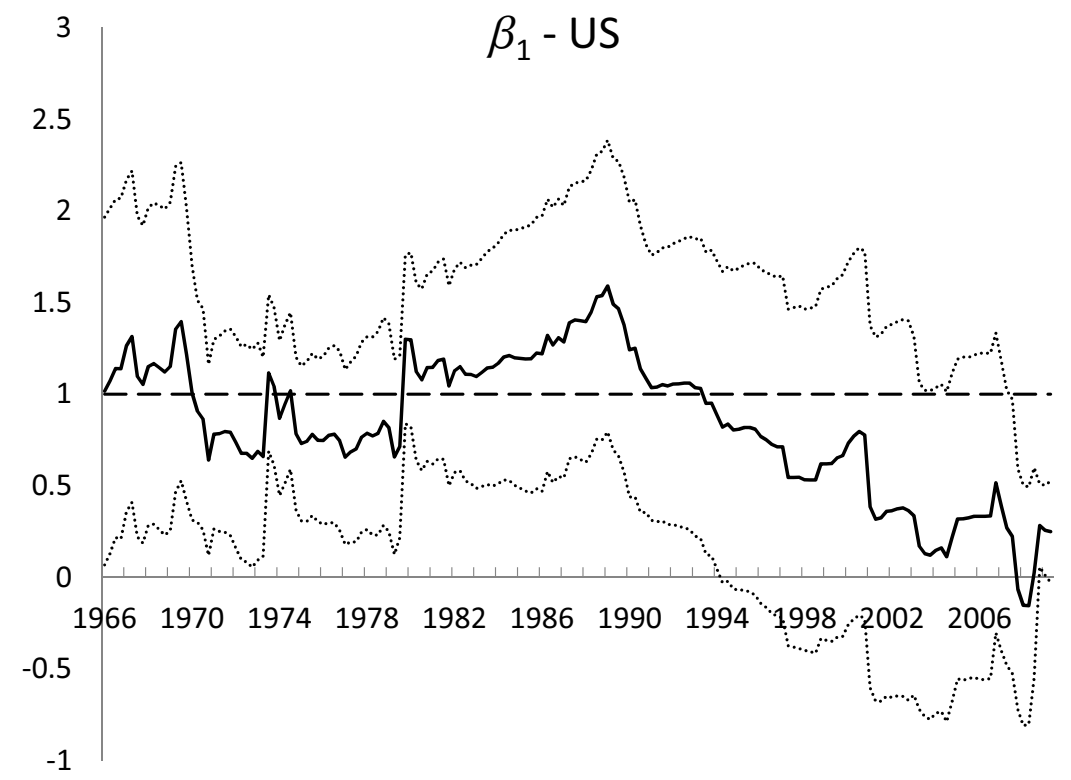

Figure 7: Estimated time varying response to inflation in US (solid line), and $90 \%$ confidence bands (doted lines). The dashed line indicates the value 1.

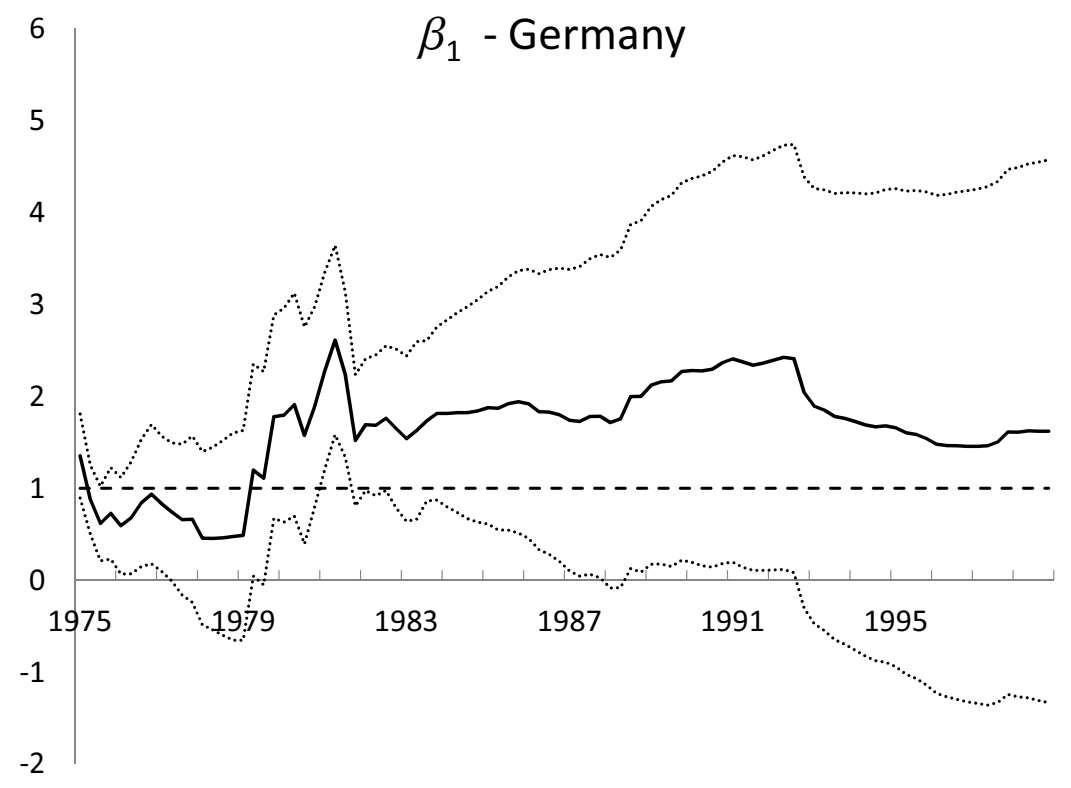

Figure 8: Estimated time varying response to inflation in Germany (solid line), and 90\% confidence bands (doted lines). The dashed line indicates the value 1 . 


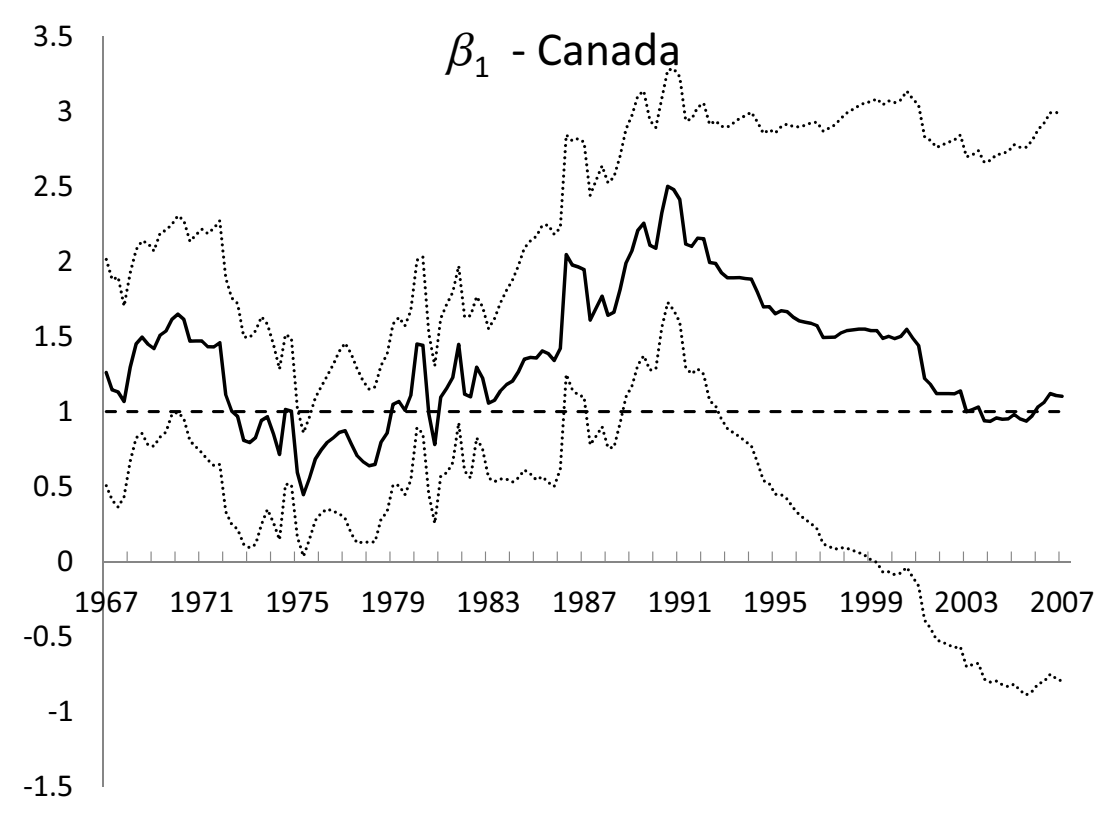

Figure 9: Estimated time varying response to inflation in Canada (solid line), and 90\% confidence bands (doted lines). The dashed line indicates the value 1.

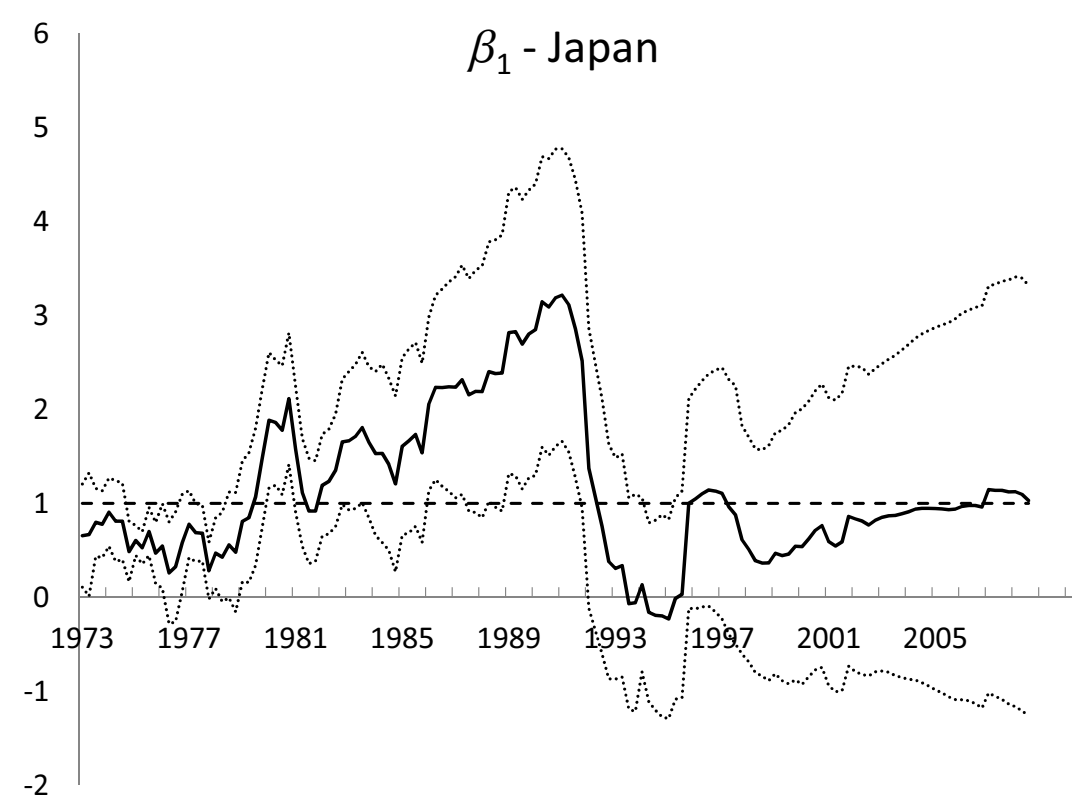

Figure 10: Estimated time varying response to inflation in Japan (solid line), and $90 \%$ confidence bands (doted lines). The dashed line indicates the value 1 . 


\section{A Appendix: Estimating State-Space Model (Connected to Section 4.1)}

\section{A.1 Step 1: Generating $\hat{\eta}_{\pi, i, t}^{*}$ and $\hat{\eta}_{y, i, t}^{*}$}

In the first step we estimate the instrumental variable equations and generate $\hat{\eta}_{\pi, i, t}^{*}$ and $\hat{\eta}_{y, i, t}^{*} \cdot{ }^{31}$ Our state space is as follows:

$$
\begin{gathered}
\nu_{i, t}=\left[\begin{array}{ll}
\mathbf{z}_{\mathbf{i}, \mathbf{t}}^{\prime} & 1
\end{array}\right]\left[\begin{array}{c}
\boldsymbol{\delta}_{\boldsymbol{\nu}, \boldsymbol{i}, \boldsymbol{t}} \\
\sigma_{\nu, i, t} v_{\nu, i, t}^{*}
\end{array}\right], \nu=\pi, y, \\
\left(\nu_{i, t}=\tilde{\mathbf{z}}_{\mathbf{i}, \mathbf{t}}^{\prime} \tilde{\boldsymbol{\delta}}_{\boldsymbol{\nu}, \boldsymbol{i}, \boldsymbol{t}}\right)
\end{gathered}
$$

and

$$
\begin{aligned}
& {\left[\begin{array}{c}
\boldsymbol{\delta}_{\boldsymbol{\nu}, \boldsymbol{i}, \boldsymbol{t}} \\
\sigma_{\nu, i, t} v_{\nu, i, t}^{*}
\end{array}\right]=\left[\begin{array}{cc}
\mathbf{I}_{\mathbf{L}} & \mathbf{0}_{\mathbf{L}} \\
\mathbf{0}_{\mathbf{L}}{ }^{\prime} & 0
\end{array}\right]\left[\begin{array}{c}
\boldsymbol{\delta}_{\boldsymbol{\nu}, \boldsymbol{i , t - 1}} \\
\sigma_{\nu, i, t-1} v_{\nu, i, t-1}^{*}
\end{array}\right]+\left[\begin{array}{c}
\boldsymbol{\zeta}_{\boldsymbol{\nu}, \boldsymbol{i , t}} \\
\sigma_{\nu, i, t} v_{\nu, i, t}^{*}
\end{array}\right],} \\
& {\left[\begin{array}{c}
\boldsymbol{\zeta}_{\boldsymbol{\nu}, \boldsymbol{i}, t} \\
\sigma_{\nu, i, t} v_{\nu, i, t}^{*}
\end{array}\right] \sim \text { i.i.d.N }\left(\left[\begin{array}{c}
\mathbf{0}_{\mathbf{L}} \\
0
\end{array}\right],\left[\begin{array}{cc}
\boldsymbol{\Sigma}_{\boldsymbol{\zeta}, \boldsymbol{\nu}, \boldsymbol{i}} & \mathbf{0}_{\mathbf{L}} \\
\mathbf{0}_{\mathbf{L}}^{\prime} & \sigma_{\nu, i, t}^{2}
\end{array}\right]\right), \nu=\pi, y .} \\
& \left(\tilde{\boldsymbol{\delta}}_{\nu, i, t}=A \tilde{\boldsymbol{\delta}}_{\nu, i, t-1}+\tilde{\boldsymbol{\zeta}}_{\nu, i, t}, \quad \tilde{\boldsymbol{\zeta}}_{\nu, \boldsymbol{i}, t} \sim i . i . d . N\left(\mathbf{0}_{\mathbf{L}+\mathbf{1}}, \boldsymbol{\Sigma}_{\tilde{\boldsymbol{\zeta}}, \boldsymbol{\nu}, \boldsymbol{i}}\right), \quad \nu=\pi, y\right)
\end{aligned}
$$

where $\boldsymbol{\Sigma}_{\zeta, \boldsymbol{\nu}, \boldsymbol{i}}$ is a diagonal variance-covariance matrix and $L$ is the number of the time varying coefficients, including a time varying constant. Also, $\sigma_{\nu, i, t}^{2}$ is time varying and is given by equation (12).

We run the Kalman filter and maximize the likelihood function, in order to generate estimates for the hyperparameters $\left(\Sigma_{\zeta, \nu, i}, a_{\nu, i, 0}, a_{\nu, i, 1}, a_{\nu, i, 2}\right)$. Then, we run the Kalmn filter again and keep $\tilde{\eta}_{\nu, i, t \mid t-1}$ and $f_{\nu, i, t \mid t-1}$, where $\tilde{\eta}_{\nu, i, t \mid t-1}=\nu_{i, t}-\nu_{i, t \mid t-1}$ and $f_{\nu, i, t \mid t-1}=$ $\mathrm{E}\left(\tilde{\eta}_{\nu, i, t \mid t-1}^{2}\right)$, for $\nu=\pi, y \cdot{ }^{32}$ We finally compute $\eta_{\nu, i, t \mid t-1}^{*}=\frac{\tilde{\eta}_{\nu, i, t \mid t-1}}{\sqrt{f_{\nu, i, t \mid t-1}}}$. This is necessary information for proceeding to the second step of the estimation process. 


\section{A.2 Step 2: Estimate the model, given $\hat{\eta}_{\pi, i, t}^{*}$ and $\hat{\eta}_{y, i, t}^{*}$}

We now estimate the model given by equations (16)-(18), (7), (8) and (6), substituting in equation (16) the elements of $\eta_{x, i, t \mid t-1}^{*}$ estimated above, in place of $\hat{\eta}_{\pi, i, t}^{*}$ and $\hat{\eta}_{y, i, t}^{*}$. We start with equation (16) and rewrite the model in the following state-space form:

$$
\begin{gathered}
r_{i, t}=C_{i, t \mid t-1}+\left[\begin{array}{ll}
\mathbf{X}_{\mathbf{i}, \mathbf{t} \mid \mathbf{t}-\mathbf{1}}^{\prime} & 1
\end{array}\right]\left[\begin{array}{c}
\boldsymbol{\beta}_{\boldsymbol{i}, \boldsymbol{t}} \\
\omega_{i, t}
\end{array}\right]+\rho_{\pi, i} \sigma_{e_{i, t}} \eta_{\pi, i, t \mid t-1}^{*}+\rho_{y, i} \sigma_{e_{i, t}} \eta_{y, i, t \mid t-1}^{*}, \\
\left(r_{i, t}=C_{i, t \mid t-1}+\tilde{\boldsymbol{X}}_{\mathbf{i}, \mathbf{t} \mid \mathbf{t}-\mathbf{1}}^{\prime} \tilde{\boldsymbol{\beta}}_{\boldsymbol{i}, \boldsymbol{t}}+\rho_{\pi, i} \sigma_{e_{i, t}} \eta_{\pi, i, t \mid t-1}^{*}+\rho_{y, i} \sigma_{e_{i, t}} \eta_{y, i, t \mid t-1}^{*}\right)
\end{gathered}
$$

and

$$
\begin{gathered}
{\left[\begin{array}{c}
\boldsymbol{\beta}_{\boldsymbol{i}, \boldsymbol{t}} \\
\omega_{i, t}
\end{array}\right]=\left[\begin{array}{cc}
\mathbf{I}_{\mathbf{4}} & \mathbf{0}_{\mathbf{4}} \\
\mathbf{0}_{\mathbf{4}}{ }^{\prime} & 0
\end{array}\right]\left[\begin{array}{c}
\boldsymbol{\beta}_{\boldsymbol{i}, \boldsymbol{t}-\mathbf{1}} \\
\omega_{i, t-1}
\end{array}\right]+\left[\begin{array}{c}
\epsilon_{i, t} \\
\omega_{i, t}
\end{array}\right],} \\
{\left[\begin{array}{c}
\boldsymbol{\epsilon}_{\boldsymbol{i}, \boldsymbol{t}} \\
\omega_{i, t}
\end{array}\right] \sim i . i . d . N\left(\left[\begin{array}{c}
\mathbf{0}_{\mathbf{4}} \\
0
\end{array}\right],\left[\begin{array}{cc}
\boldsymbol{\Sigma}_{\boldsymbol{\epsilon}, \boldsymbol{i}} & \mathbf{0}_{\mathbf{4}} \\
\mathbf{0}_{\mathbf{4}}{ }^{\prime} & \left(1-\rho_{\pi, i}^{2}-\rho_{y, i}^{2}\right) \sigma_{e_{i, t}}^{2}
\end{array}\right]\right),} \\
\left(\tilde{\boldsymbol{\beta}}_{\boldsymbol{i}, \boldsymbol{t}}=\mathbf{B} \tilde{\boldsymbol{\beta}}_{\boldsymbol{i}, \boldsymbol{t}-\mathbf{1}}+\tilde{\boldsymbol{\epsilon}}_{\boldsymbol{i}, \boldsymbol{t}}, \quad \tilde{\boldsymbol{\epsilon}}_{\boldsymbol{i}, \boldsymbol{t}} \sim \operatorname{i.i.d.N}\left(\mathbf{0}_{\mathbf{5}}, \boldsymbol{\Sigma}_{\tilde{\boldsymbol{\epsilon}}, \boldsymbol{i}}\right)\right)
\end{gathered}
$$

where $\boldsymbol{\Sigma}_{\epsilon, i}$ is a $4 \times 4$ diagonal matrix with $\sigma_{\epsilon, k, i}^{2}$ as diagonal elements, for $k=0,1,2,3$, and $\sigma_{e_{i, t}}^{2}$ is given by equation (6).

The log-likelihood function that we maximize is:

$$
\ln L_{r}=\sum_{t=1}^{T} \ln \left[\frac{1}{\sqrt{2 \pi f_{i, t \mid t-1}}} \exp \left(-\frac{\left(r_{i, t}-r_{i, t \mid t-1}\right)^{2}}{2 f_{i, t \mid t-1}}\right)\right]
$$

where $r_{i, t \mid t-1}=\mathrm{E}\left(r_{i, t} \mid \bar{C}_{i, T}, \overline{\boldsymbol{X}}_{\boldsymbol{i}, \boldsymbol{T}}, \bar{r}_{i, T-1}\right)$, for $\bar{g}=\left[\begin{array}{llll}g_{1} & g_{2} & \ldots & g_{T}\end{array}\right]^{\prime}$ and $f_{i, t \mid t-1}=\mathrm{E}\left(\eta_{i, t \mid t-1}^{2}\right)$.

The first round of Kalman filter iterations estimate the model's hyperparameters $\left(\rho_{\pi, i}, \rho_{y, i}, \boldsymbol{\Sigma}_{\tilde{\epsilon}, \boldsymbol{i}}\right)$ maximizing the likelihood function. After estimating the hyperparameters, we run the Kalman filter for the second time in order to get an estimate for $\boldsymbol{\beta}_{\boldsymbol{i}, \boldsymbol{t}}$ from the first four rows of $\tilde{\boldsymbol{\beta}}_{\boldsymbol{i}, \boldsymbol{t}}$. The estimate of $\boldsymbol{\beta}_{\boldsymbol{i}, \boldsymbol{t}}$ is given correctly by iterating the Kalman filter as usually. However, given the two-step approach for solving the endogeneity issue and the usage of 
the control function, the standard errors of the coefficients face the problem of generated regressors (see Pagan, 1984). To address this issue, we augment the Kalman filter in order to get estimates for $\operatorname{Var}\left(\boldsymbol{\beta}_{\boldsymbol{i}, \boldsymbol{t}} \mid I_{t-1}\right)$ and $\operatorname{Var}\left(\boldsymbol{\beta}_{\boldsymbol{i}, \boldsymbol{t}} \mid I_{t}\right)$ from the first $4 \times 4$ block of $\boldsymbol{P}_{\boldsymbol{i}, \boldsymbol{t} \mid \boldsymbol{t}-\mathbf{1}}^{\boldsymbol{1}}$ and $P_{i, t \mid t}^{*}$ :

$$
\begin{gathered}
\boldsymbol{P}_{\boldsymbol{i}, \boldsymbol{t} \mid \boldsymbol{t}-\mathbf{1}}^{*}=\mathbf{B} \boldsymbol{P}_{\boldsymbol{i}, \boldsymbol{t}-\mathbf{1} \mid \boldsymbol{t}-\mathbf{1}}^{*} \mathbf{B}^{\prime}+\boldsymbol{\Sigma}_{\tilde{\boldsymbol{\epsilon}}, \boldsymbol{i}}, \\
f_{i, t \mid t-1}^{*}=\tilde{\boldsymbol{X}}_{\mathbf{i}, \mathbf{t} \mid \mathbf{t}-\mathbf{1}}^{\prime} \boldsymbol{P}_{\boldsymbol{i}, \boldsymbol{t} \mid \boldsymbol{t}-\mathbf{1}} \tilde{\boldsymbol{X}}_{\boldsymbol{i}, \boldsymbol{t} \mid \boldsymbol{t}-\mathbf{1}}+\left(\rho_{\pi, i}^{2}+\rho_{y, i}^{2}\right)^{2} \sigma_{e_{i, t}}^{2} \\
\boldsymbol{P}_{\boldsymbol{i}, \boldsymbol{t} \mid \boldsymbol{t}}^{*}=\boldsymbol{P}_{\boldsymbol{i}, \boldsymbol{t} \mid \boldsymbol{t}-\mathbf{1}}-\boldsymbol{P}_{\boldsymbol{i}, \boldsymbol{t} \mid \boldsymbol{t}-\mathbf{1}} \tilde{\boldsymbol{X}}_{\boldsymbol{i}, \boldsymbol{t} \mid \boldsymbol{t}-\mathbf{1}} f_{i, t \mid t-1}^{*-1} \tilde{\boldsymbol{X}}_{\mathbf{i}, \mathbf{t} \mid \mathbf{t}-\mathbf{1}}^{\prime} \boldsymbol{P}_{\boldsymbol{i}, \boldsymbol{t} \mid \boldsymbol{t}-\mathbf{1}}
\end{gathered}
$$

While the true variance of $\boldsymbol{\beta}_{\boldsymbol{i}, \boldsymbol{t}}$ is calculated using the variance of $e_{i, t}, \boldsymbol{P}_{\boldsymbol{i}, \boldsymbol{t} \mid \boldsymbol{t}}$ is calculated using the variance of $\omega_{i, t}$, which is only a part of the variance of $e_{i, t}$. The above adjustment solves this issue.

\section{B Appendix: Testing for cointegration (Connected to Sec- tion 4.2)}

To examine whether the conduct of monetary policy and, more importantly, its changes followed similar pattern across developed countries we concentrate on the analysis of the dependence between the estimated paths of coefficients. In particular, we want to know whether we can find a long-run cross-country relationship in the responses to inflation in the Taylor rules.

Our empirical methodology is dictated by the assumption of the unit root in the timevarying parameter representation of the monetary policy. Recall that the evolution of monetary policy is given by equation (7),

$$
\beta_{j, i, t}=\beta_{j, i, t-1}+\epsilon_{j, i, t}, \quad \forall j, i,
$$

so in order to study the existence of cross-country relationship between responses to inflation in Taylor rule, we have to take into account the non-stationary nature of the time-series in question. 
Engle and Granger (1987) suggests that even though economic variables might be nonstationary there might exists a stable well-defined linear long-run relationship between these variables. If we define $\boldsymbol{\beta}_{\mathbf{1 , t}}=\left[\beta_{1,1, t}, \beta_{1,2, t}, \ldots, \beta_{1, k, t}\right]^{\prime}$ as a vector of responses to inflation in the Taylor rules in all the countries then given equation (7) each element of $\boldsymbol{\beta}_{\mathbf{1}, \boldsymbol{t}}$ is $I(1)$. To study the existence of the commonality in the conduct of monetary policy we ask whether we can find a cointegrated relationship in $\boldsymbol{\beta}_{\mathbf{1}, \boldsymbol{t}}$, i.e. a vector $\boldsymbol{\xi}$ such that $\boldsymbol{\xi}^{\prime} \boldsymbol{\beta}_{\mathbf{1 , t}}$ is $I(0)$. If this is the case, we can say that there exists a "long-run" relationship in how monetary policy is conducted across countries. If such relation cannot be found we conclude that there does not exist a long-run common pattern in monetary policy response to inflation.

\section{B.1 Testing for cointegration}

To test for cointegration consider the $\operatorname{VAR}(p)$ representation of a $k \times 1$ vector $\boldsymbol{\beta}_{\mathbf{1}, \boldsymbol{t}}$,

$$
\boldsymbol{\beta}_{1, t}=\Theta_{1} \boldsymbol{\beta}_{1, t-1}+\ldots+\Theta_{p} \boldsymbol{\beta}_{1, t-p}+u_{1, t}
$$

and its vector error-correction form

$$
\Delta \boldsymbol{\beta}_{1, t}=\boldsymbol{\Gamma}_{1} \Delta \boldsymbol{\beta}_{1, t-1}+\ldots+\boldsymbol{\Gamma}_{p-1} \Delta \boldsymbol{\beta}_{1, t-p+1}+\boldsymbol{\Pi} \boldsymbol{\beta}_{1, t-1}+\boldsymbol{u}_{1, t}, \quad t=1, \ldots, T
$$

where $\Delta$ denotes the difference operator; $\boldsymbol{\Gamma}_{\boldsymbol{i}}=\sum_{\iota=i+1}^{p} \boldsymbol{\Theta}_{\iota}$ and $\boldsymbol{\Pi}=\boldsymbol{\Theta}_{\mathbf{1}}+\ldots+\boldsymbol{\Theta}_{\boldsymbol{p}}-\boldsymbol{I}_{\boldsymbol{k}}$ are $p \times p$ matrices of coefficients; and $\mathbf{u}_{\mathbf{1}, \mathbf{t}}$ is an error vector with i.i.d. multivariate distribution with mean 0 and covariance matrix $\Omega{ }^{33}$ In our baseline specification we set $p=1$ so equations (25) and (26) have the following form:

$$
\begin{aligned}
\boldsymbol{\beta}_{1, t} & =\Theta_{1} \boldsymbol{\beta}_{1, t-1}+\mathbf{u}_{1, \mathbf{t}}, \\
\Delta \boldsymbol{\beta}_{1, t} & =\boldsymbol{\Pi} \boldsymbol{\beta}_{1, t-1}+\mathbf{u}_{1, \mathbf{t}}
\end{aligned}
$$

where $\boldsymbol{\Pi}=\boldsymbol{\Theta}_{1}-\boldsymbol{I}_{\boldsymbol{k}}$ and $k=7$.

The hypothesis of cointegration can be stated in terms of the matrix $\Pi$. This matrix, 
which satisfies $\boldsymbol{\Pi} \boldsymbol{\beta}_{\mathbf{1}, \boldsymbol{t}-\mathbf{1}} \sim I(0)$, can be written as:

$$
\Pi=\alpha \xi^{\prime}
$$

where $\boldsymbol{\xi}$ is $k \times r$ matrix of cointegrating vectors such that $\boldsymbol{\xi}^{\prime} \boldsymbol{\beta}_{\mathbf{1}, t}$ is $I(0)$; $\boldsymbol{\alpha}$ is $k \times r$ matrix of associated weights; and $r=\operatorname{rank}(\boldsymbol{\Pi})$. If $r=0$ then $\boldsymbol{\Pi}=\mathbf{0}$ and there does not exist a linear combination of the elements of $\boldsymbol{\beta}_{\mathbf{1}, \boldsymbol{t}}$ that is stationary, while if $r=k, \boldsymbol{\beta}_{\mathbf{1}, t}$ is stationary. When $0<r<k$, there exists $r$ stationary linear combinations of the elements of $\boldsymbol{\beta}_{1, t}$ and $k-r$ independent stochastic trends.

To test for the number of cointegrating relationships we follow the likelihood ratio test presented by Johansen and Juselius (1990) and Johansen (1991). ${ }^{34}$ It can be shown that (i) the maximum likelihood estimate for $\boldsymbol{\xi}$ equals the matrix with the $r$ eigenvectors corresponding to the $r$ largest eigenvalues, $\lambda_{j}$, of $\boldsymbol{\Pi}$, and (ii) if the $\operatorname{rank}(\boldsymbol{\Pi})=r$ and $\lambda_{1} \leq \lambda_{2} \leq \cdots \leq \lambda_{r}$ then for $k-r$ smallest eigenvalues of matrix $\Pi, \log \left(1-\lambda_{j}\right)=0$, $j=r+1, \ldots, k$. Then, the Trace statistics for the null hypothesis $r \leq r_{0}$ against the alternative $H_{1}: r_{0} \leq r \leq k$ equals:

$$
\lambda_{\text {trace }}\left(r_{0}\right)=-T \sum_{j=r_{0}+1}^{k} \log \left(1-\hat{\lambda}_{j}\right) \text {, }
$$

where $\hat{\lambda}_{j}, j=1, \ldots, k$ denotes estimated eigenvalues of $\boldsymbol{\Pi}$. The maximum eigenvalue test, on the other hand, tests $H_{0}: r \leq r_{0}$ versus $H_{1}: r=r_{0}+1$ using $\lambda_{\max }$ statistics:

$$
\lambda_{\max }=-T \log \left(1-\hat{\lambda}_{t_{0}+1}\right) .
$$

Both tests are performed sequentially for $r=0,1, \ldots, k-1$ with the testing sequence terminating when the $H_{0}: r \leq r_{0}$ is not rejected for the first time. When this happens, we conclude that there are $r_{0}$ cointegrating vectors.

Note that the determination of the order, $p$, of the VAR representation (25) is important for both tests due to bias-efficiency trade-off. In general, too low $p$, i.e. too few lags in 
the model leads to rejection of the null hypothesis too easily, while too high $p$ decreases the power of the tests. Taking into account how $\beta_{i, j, k}$ 's are generated, in our baseline specification we will consider the case with $p=1$. Also, we will allow for an intercept in the cointegrating relationship.

\section{B.2 Bootstrapping cointegration}

The asymptotic distributions of tests statistics (30) and (31) are multivariate extensions of the Dickey-Fuller distributions and depends on a number of non-stationary components under the null hypothesis as well as on the presence of constant and/or trend. However, since $\boldsymbol{\beta}_{1, t}$ are generated regressors, instead of using standard critical values, e.g. presented in MacKinnon et al. (2000), we bootstrap cointegration regression and simulate the distribution of Johansen statistics.

Our approach is similar to that considered in Psaradakis (2001) and Chang et al. (2006) but, as far as we know, we are the first to adapt it to VAR-based cointegration test and the Johansen's statistics. To obtain the bootstrap samples of $\boldsymbol{\beta}_{\mathbf{1}, \boldsymbol{t}}^{*}$ for $\boldsymbol{\beta}_{\mathbf{1}, \boldsymbol{t}}$ we proceed as follows.

Step 1: Estimate the regression (28) under the restriction of $h$ cointegrated vectors and compute the $\hat{\mathbf{u}}_{\mathbf{1 , t}}=\Delta \boldsymbol{\beta}_{\mathbf{1 , t}}-\hat{\boldsymbol{\alpha}}\left(\hat{\boldsymbol{\xi}}^{\prime} \boldsymbol{\beta}_{\mathbf{1 , t}}+\hat{\boldsymbol{c}}\right)$.

Step 2: Construct the VAR-sieve bootstrap for $\hat{\mathbf{u}}_{\mathbf{1}, \mathbf{t}}$ by estimating an AR(q) model for $\hat{\mathbf{u}}_{\mathbf{1}, \mathbf{t}}$,

$$
\hat{\mathbf{u}}_{\mathbf{1}, \mathbf{t}}=\hat{\Phi}_{1} \hat{\mathbf{u}}_{\mathbf{1}, \mathbf{t}-\mathbf{1}}+\ldots+\hat{\Phi}_{q} \hat{\mathbf{u}}_{\mathbf{1}, \mathbf{t}-\mathbf{q}}+\hat{\nu}_{q t}
$$

with the choice of the lag length $q$ based on BIC, and constructing centered fitted residuals

$$
\nu_{t}^{*}=\hat{\nu}_{q t}-\frac{1}{n} \sum_{t=1}^{T} \hat{\nu}_{q t} .
$$

Step 3: Repeat $B$ times 
(a): Draw $T$ observation from $\left(\nu_{t}^{*}\right)$ and construct

$$
\mathbf{u}_{\mathbf{1}, \mathbf{t}}^{*}=\hat{\Phi}_{1} \mathbf{u}_{\mathbf{1 , t}-\mathbf{1}}^{*}+\ldots+\hat{\Phi}_{q} \mathbf{u}_{\mathbf{1}, \mathbf{t}-\mathbf{q}}^{*}+\nu_{t}^{*}
$$

Set $\mathbf{u}_{\mathbf{1}, \mathbf{0}}^{*}=\mathbf{u}_{1,-1}^{*}=\ldots=\mathbf{u}_{1,-\mathbf{q}+\mathbf{1}}^{*}=0$.

(b): Construct $\left\{\boldsymbol{\beta}_{1, t}^{*}\right\}$

$$
\beta_{\mathbf{1}, \mathbf{t}}^{*}=\beta_{\mathbf{1}, \mathbf{0}}^{*}+\sum_{k=1}^{t} \mathbf{u}_{\mathbf{1}, \mathbf{k}}^{*} .
$$

$(c)$ : Use the bootstrap sample $\left\{\boldsymbol{\beta}_{1, t}^{*}\right\}$ to estimate the VECM model (28) and compute the Johansen statistics, $\lambda_{\max }$ and $\lambda_{\text {trace }}$.

$(d)$ : Go to $(a)$.

Step 5: Test if the null hypothesis of $h$ cointegrating vectors can be rejected.

We repeat this process for every null hypothesis of $h$ cointegrating vectors. ${ }^{35}$

Once we determined the number of cointegrating vectors we can recover the estimates of the cointegrating vector $\boldsymbol{\xi}$ and associated matrix of weights, $\boldsymbol{\alpha}$. Since different combinations of $\boldsymbol{\xi}$ and $\boldsymbol{\alpha}$ gives $\boldsymbol{\Pi}=\boldsymbol{\alpha} \boldsymbol{\xi}^{\prime}$, that is $\boldsymbol{\xi}$ and $\boldsymbol{\alpha}$ are not uniquely identified, some normalization assumptions on $\boldsymbol{\xi}$ are necessary, as discussed in Section 6 that presents the results. 